\title{
Moped Scooter Sharing: Citizens' Perceptions, Users' Behavior, and Implications for Urban Mobility
}

\author{
Álvaro Aguilera-García ${ }^{1, *(D)}$, Juan Gomez ${ }^{1}\left[\right.$, Natalia Sobrino ${ }^{2}$ and Juan José Vinagre Díaz ${ }^{3}(0)$ \\ 1 Transport Research Centre (TRANSyT), Universidad Politécnica de Madrid, 28040 Madrid, Spain; \\ juan.gomez.sanchez@upm.es \\ 2 Transport Research Centre (TRANSyT), Department Civil Engineering, Construction, Infrastructure and \\ Transportation, Universidad Politécnica de Madrid, 28014 Madrid, Spain; natalia.sobrino@upm.es \\ 3 Group Biometry, Biosignals, Security, and Smart Mobility, Departamento de Matemática Aplicada a las \\ Tecnologías de la Información y las Comunicaciones, Escuela Técnica Superior de Ingenieros de \\ Telecomunicación, Universidad Politécnica de Madrid, 28040 Madrid, Spain; juanjose.vinagre@upm.es \\ * Correspondence: alvaro.aguilera@upm.es
}

check for updates

Citation: Aguilera-García, Á.;

Gomez, J.; Sobrino, N.; Vinagre Díaz, J.J. Moped Scooter Sharing: Citizens' Perceptions, Users' Behavior, and Implications for Urban Mobility. Sustainability 2021, 13, 6886. https:// doi.org/10.3390/su13126886

Academic Editor: Elżbieta Macioszek

Received: 10 May 2021

Accepted: 15 June 2021

Published: 18 June 2021

Publisher's Note: MDPI stays neutral with regard to jurisdictional claims in published maps and institutional affiliations.

Copyright: (c) 2021 by the authors. Licensee MDPI, Basel, Switzerland. This article is an open access article distributed under the terms and conditions of the Creative Commons Attribution (CC BY) license (https:// creativecommons.org/licenses/by/ $4.0 /)$

\begin{abstract}
In recent years, moped-style scooter sharing is gaining increasing attention in many urban areas worldwide. Nevertheless, research contributions are still limited, unlike other shared mobility systems. This paper is aimed at providing a first insight on moped sharing demand by exploring the usage and opinions towards this new mobility alternative. To that end, the research exploits the data from a web-based survey conducted in Spain, one of the countries with the largest implementation around the world in terms of the shared e-mopeds fleet. Kruskal-Wallis tests were conducted to identify the segment of the urban population that is more likely adopted moped sharing, and additional statistical mean differences in specific variables concerning moped sharing were carried out. The paper also provides a better understanding of the shared mopeds market and some implications for urban mobility, such as the potential role of shared mopeds in reducing vehicle ownership and its effect on urban modal shift. Furthermore, two discrete choice models were developed to (i) analyze the key drivers determining the willingness to use moped sharing, and (ii) explore individuals' opinions on whether owning a private vehicle will not be a need in the future. The results indicate that age, occupation, income, and environmental awareness seem to be among the main reasons behind the potential use of these services in the future. The results may be useful for both operators and transport planners when designing actions and policy efforts addressing this mobility option and urban mobility in general.
\end{abstract}

Keywords: moped scooter sharing; user attitudes; survey; sharing economy; shared mobility; new mobility services; Spain

\section{Introduction}

Shared mobility solutions have generated special attention in recent years and their popularity has grown in several cities throughout the world. According to Fulton [1], these kinds of innovative and cleaner mobility solutions, along with vehicle electrification and automation, are considered one of the three revolutions in urban transportation systems worldwide. In recent years, shared mobility services, such as bikesharing, carsharing, and ridehailing have emerged [2], with a stronger presence in urban areas, and clear effects on urban mobility behavior and sustainability. While these mobility options started to operate some years ago, currently we are experiencing a further development in urban shared mobility and new options have been recently incorporated, such as e-kick scooter sharing or e-moped scooter sharing. The latter, best known in Spain as motosharing, has been exponentially developed over the last few years. Shared mopeds can represent an attractive and flexible mobility alternative for particular segments of the population, which may contribute to moving urban transport towards sustainability. 
It is well known that urban areas are currently facing different challenges-changes in the demographics and lifestyle of citizens, environmental concerns, or economic issues-with a great impact on mobility patterns. For instance, around $75 \%$ of the European population lives in urban areas [3], which is having a notable effect on urban mobility demand and generating significant externalities coming from transport. These facts have impacts on living standards, quality of life, and the health of people, with growing importance in parallel with the increase in world urbanization. Furthermore, air pollution involves major environmental risks for citizens, as pointed out by WHO [4]. This global trend will continue in the future, since around $70 \%$ of the world's population is expected to live in cities by 2050 . To overcome these challenges, urban authorities are putting air quality plans and mobility strategies into practice, in which the provision of sustainable transport alternatives is a must. In this sense, shared mobility can represent an opportunity for local governments to move urban transport towards sustainability, and deeper knowledge about all these new mobility services is needed to properly include them into current transport and air quality local strategies.

Moped sharing is gaining increasing attention in European cities, where operators typically provide fully electric free-floating motor scooters, including motorcycles, mopeds, and Vespa-like vehicles. As long as shared electric mopeds present noticeable advantages compared to some alternative transport modes (e.g., lower air pollution and noise, reduction in road congestion, etc.), moped sharing represents a driver to be considered by local governments to encourage sustainable urban transport and improve the livability of cities. To date, the existing research contributions on shared mobility have investigated primarily carsharing, bikesharing, and ridehailing services. Nevertheless, in the scientific literature, almost no efforts have been devoted to studying electric moped scooter sharing, despite its relevant growth in recent years. Therefore, there is a need to explore citizens' perceptions, users' behavior, and implications for urban mobility of moped sharing.

Within the above context, this research is aimed at exploring the usage and opinions towards this urban mobility alternative. To that end, a web-based questionnaire was disseminated in Spain, the country with the largest implementation of shared e-mopeds in Europe [5], specifically in those Spanish cities with moped sharing services available. The quantitative analysis of the survey, together with the development of discrete choice models, provides a better understanding of the moped sharing market as well as some implications for urban mobility, which is of great interest for both operators and transport planners when designing actions and policy efforts addressing this environmentally friendly mobility option. Furthermore, the paper explores the relationship and impact of moped sharing on other alternative modes of transport, as well as how moped sharing services are perceived by both users and non-users. We should point out that the electric kick-style scooter market, also known as standing electric scooter sharing, is not analyzed in this research. It is also important to note that the survey was conducted before the COVID-19 pandemic, but some consideration has been made about the use of shared mopeds on the basis of post-COVID-19 times.

This paper is organized as follows. Section 2 outlines the scientific literature relevant to our study. Section 3 describes the state of implementation of moped sharing. The survey conducted and the data sample used for this research are described in Section 4, while Section 5 outlines the methodology adopted in this research. Section 6 presents the main findings and discusses the modeling results. Finally, Section 7 deals with the main conclusions and proposes further research initiatives.

\section{Literature Review: Shared Mobility and Travel Behavior}

Shared mobility services, such as carsharing, bikesharing, ridesourcing, or moped sharing, are influencing travel behavior, mobility patterns, and modal shift [6-8], and competing with more traditional modes of transportation. According to NASEM [9], the adoption of these services is having some implications for the overall transportation system, e.g., shared mobility options may substantially complement public transit, enhancing 
sustainable urban mobility. Furthermore, moped sharing can increase the efficiency of vehicle use, since private mopeds and motorcycles stand idle most of the time.

As pointed out by Shaheen and Chan [10], shared mobility is an innovative way of transportation, in which users gain short-term access to vehicles on an as-needed basis. This has brought great changes in, e.g., car ownership or how individuals plan and make their trips. Particularly, moped sharing systems have been widely adopted by cities around the world. This mobility service has some specific features that make it an interesting option to be considered when traveling in urban areas. For instance, moped sharing can increase the accessibility and flexibility provided by fixed-route and fixed-schedule public transit services. Additionally, scooter sharing includes another type of service, the so-called kick scooter sharing or standing electric scooter sharing [11], which is not analyzed in this research, since it started to operate after conducting the survey campaign described in this research. In addition, kick scooter sharing is an effective solution to the last-mile issue, while moped sharing could not be considered as a shared micromobility mode as it is a faster alternative, and allows users to cover longer distances.

In the recent scientific literature, many research contributions can be found on shared mobility from the user behavioral perspective. For instance, in the United States (US), it has been noted that individuals adopting shared mobility systems tend to be young adults, highly educated, and live in the dense central parts of cities [12-14]. Other studies based on descriptive statistics, such as Circella et al. [2], showed that the popularity of these systems is particularly higher among millennials and those people living in high-density urban areas. According to Taylor et al. [14] and Tyndall [15], the wider shared mobility supply could have implications for user's preferences, e.g., impacting on private vehicle ownership decisions or public transit patronage. Furthermore, an increasing number of papers have examined the environmental, social, and behavioral impacts of shared mobility on the basis of a set of ridesharing, carsharing, bikesharing, and ridesourcing studies [16-18].

To date, the behavioral literature about shared mobility services has found two different areas. The first one focuses on analyzing the factors determining the adoption and frequency of use of shared mobility services. The second one is related to their impacts on travel behavior (e.g., impacts on activity patterns or mode choice decisions). The current literature has mainly covered bikesharing [19-24], carsharing [15,25-28], on-demand ride services [29], and recently kick scooter sharing [30,31]. The scarcity of scientific literature on moped sharing is a point underlined by Howe and Bock [32]. As can be observed in Figure 1, the literature devoted to shared mopeds is limited, which greatly contrasts with other shared mobility systems such as carsharing. In this regard, we have revised scientific databases such as Scopus and searched all relevant, up-to-date research in the field of transportation, concerning all types of shared mobility options in urban areas.

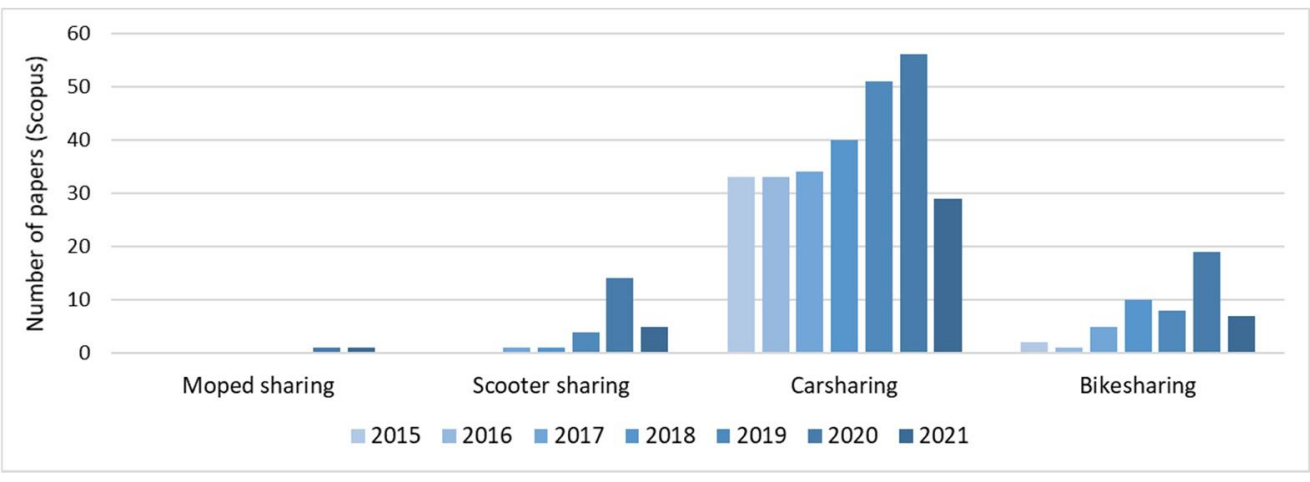

Figure 1. Main trends of scientific literature over the years by entering the keywords on Scopus.

To our knowledge, the studies by Degele et al. [33], Aguilera-García et al. [34], and Pérez-Fernández and García-Palomares [35] are the only existing research papers concerning moped sharing carried out up-to-date. Firstly, Degele et al. [33] identified customer 
segments of moped scooter sharing based on data usage in Germany. Secondly, AguileraGarcía et al. [34] adopted a generalized ordered logit model to explore the key factors determining the use of shared e-mopeds. Finally, Pérez-Fernández and García-Palomares [35] employed GIS location-allocation models and GPS data to identify optimal locations for parking spaces for moped sharing in the center of Madrid. Nevertheless, further important aspects were not explored in these studies. Shared mopeds present many uncertainties, such as adoption levels, profitability, impacts on urban livability and sustainability, etc., which are still not addressed in the literature. Then, more research contributions are needed in this field, since understanding the use of moped sharing is crucial for planners, administrators, and transport providers to properly insert it within the urban transport system, and achieve a more sustainable urban mobility [35].

Additional insight could be drawn based on the online survey used by Aguilera-García et al. [34]. Therefore, an in-depth exploratory analysis of the data (sociodemographic characteristics, mobility patterns, opinions towards moped sharing, main reasons for using/not using these services, aspects to be improved, etc.) is conducted in this research. Furthermore, its effect on the urban modal shift to alternative transport modes and its potential relationship in reducing vehicle ownership need is explored. Finally, this research develops a choice modeling framework to tackle the key factors determining the potential use of moped sharing.

\section{The State of Moped Sharing}

\subsection{The Recent Moped-Style Scooter Sharing Surge}

Bikesharing was the first sharing mobility scheme introduced in urban areas in the 1990s, followed by electric carsharing systems that started to operate in the 2000s. Afterward, moped sharing was first implemented in San Francisco (US) in 2012. Then, starting in 2015, the market development of moped-style scooter sharing began to spread all over the world (see Figure 2). In 2017, there was notable growth in the international market, since 8000 mopeds were deployed [36], and in the following year this reached a total of 25,000 shared mopeds worldwide [37]. In 2019, the moped sharing market increased by $164 \%$ in terms of fleet, with approximately 66,000 shared mopeds available. As can be seen in Figure 2, more than 85 cities worldwide have adopted this shared mobility service, with up to 5 million registered users [5]. To date, the European market is leading, reaching more than $50 \%$ of the global fleet of shared mopeds, as noted by Howe and Jakobsen [5]. Furthermore, Spain is the biggest country market, after India, with more than 13,500 mopeds in operation [5]. In 2020, the biggest fleets were in Bangalore, Taipei, Barcelona, Madrid, Milan, and Paris.

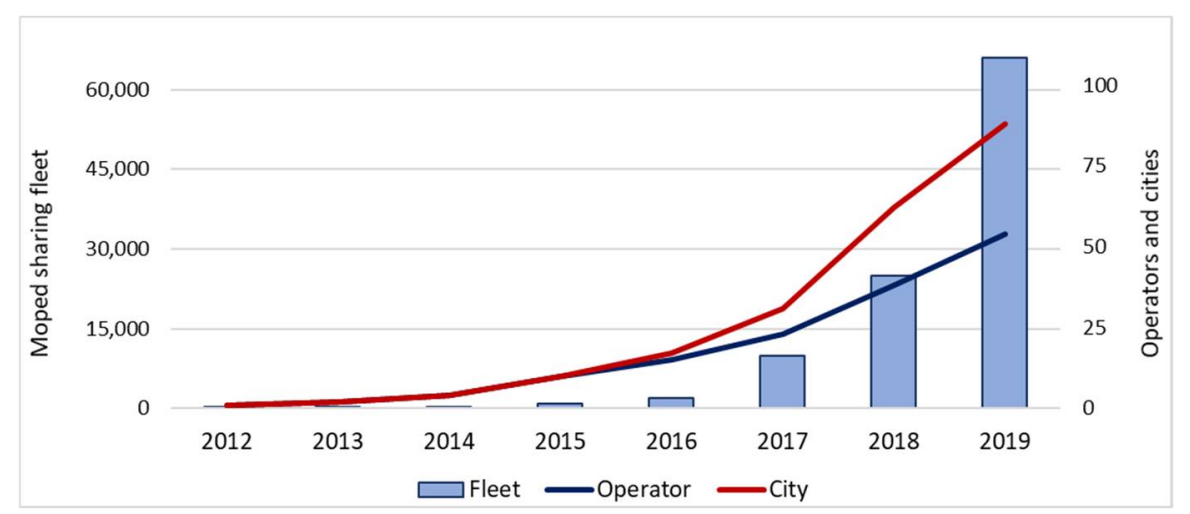

Figure 2. Fleet and number of operators of moped sharing worldwide, and cities that have adopted this shared mobility service (adapted from Howe and Jakobsen [5]).

In recent years, the potential market is thriving globally [38]. The recent growth of shared mobility options in many urban areas worldwide, as a new and more sustainable way of transportation, is contributing to shifting mobility trends from ownership to service 
use [39]. Moped sharing is a new actor for the daily life of cities that should fit into the current strategies for sustainable mobility [35]. However, planning instruments do not yet incorporate these forms of mobility in the majority of cities. As commented in Section 2, the research devoted to moped sharing is still limited, and further contributions are needed to determine and assess the effects on travel behavior, environment, infrastructure, and safety. For these reasons, understanding the use of moped sharing is decisive for transport operators, planners, and public administration to properly insert it within the urban transport system and achieve more sustainable urban transport.

As with any shared mobility mode, moped sharing systems may have the following two types of business models: free-floating and station-based [32]. The former, in which shared mopeds can be picked up and left within a geo-fenced area, is clearly predominate. Indeed, almost all companies worldwide operate with free-floating shared mopeds [37]. Furthermore, if we look at the rest of the world, all apart from India, 99\% of the mopeds are electric [5]. Additionally, given that these systems generally employ fully electric mopeds, it represents an environmentally friendly transportation alternative for urban areas. Among all the electric vehicles currently available, e-mopeds evidence significant low-carbon benefits over the rest, since electric two-wheelers are smaller, lighter, and more mobile, making them more energy-efficient and environmentally sustainable [40].

Shared mopeds or motorcycles are designed to travel on public roadways and generally have a less stringent driving licensing requirement than other motorized vehicles [11], e.g., carsharing. In other shared mobility options, such as bikesharing or kick scooter sharing, the driver's license verification is not necessary. In addition, motorcycle and moped legislation requires helmet use, unlike other modes of transportation such as bikes or standing scooters.

\subsection{The State of Moped Sharing in Spanish Urban Areas}

In recent years, electric moped sharing has generated considerable interest in Spain. As mentioned above, recently Spain has reached a fleet of 13,520 mopeds, with a market growth of 500\% in 2018 [37] and 52\% in 2019 [5], being the most important European market and the second country with the largest implementation worldwide. Currently, moped sharing is present in many regions, not only in big cities, but also in medium-sized cities such as Cadiz or Cordoba. Nevertheless, the largest fleets are in the big cities, for example Madrid and Barcelona, which reach $81 \%$ of the total fleet of the country to date.

In Spain, all the existing moped sharing companies operate by using free-floating schemes. Furthermore, all shared mopeds are electric in Spain, which is particularly relevant, since in this country electric vehicles do not have access restrictions in city centers. This transport option also benefits from free on-street parking, providing a practical alternative for people to drive in urban areas. For all those reasons, the city center is usually its main area of operation. Nevertheless, in medium-size cities, moped sharing also has a noticeable presence in outlying districts.

All operators offer similar pricing and have a scheme based on the time of use, with a current rate ranging between $0.24 €$ and $0.28 €$ per minute. The price structure could be a barrier if vehicles are rented for a long time, so operators frequently offer promotion packs that can be acquired in advance to get a better deal as a way to encourage their use. Since there is neither a fixed monthly subscription fee nor a significant sign-up fee in Spain, individuals tend to join several operators at the same time. This can make it economically favorable for people who use these systems regularly, since some mobile apps offer integrated information regarding moped sharing supply (comprising several operators) in certain cities, namely, the situation of mopeds in real-time, the estimated cost of a certain itinerary, etc. Conversely, reservation and payment procedures are still not integrated across operators.

Currently, up to 10 different companies provide free-floating moped sharing services in Spain. Furthermore, there are some operators, as is the case of Movo, that do not simply offer mopeds, but also supply shared bicycles or kick scooters as part of their 
overall concept of mobility service. This trend of integration of the services is expected to continue in the next years. Furthermore, moped sharing coexists with other shared mobility alternatives in many Spanish cities. Bikesharing and station-based carsharing are available in many Spanish cities, while free-floating carsharing services are operated in Madrid by four different private companies. Additionally, kick scooter sharing has also become available in many urban areas, such as Malaga, Madrid, Valencia, or Zaragoza. This innovative vehicle sharing model is not analyzed in this research, since it started to operate after conducting the survey campaign described in this research.

Finally, Figure 3 shows a map of Madrid and Barcelona, among the cities with the largest implementation of shared e-mopeds worldwide. This map indicates the defined service area of two well-known moped sharing companies operating in both cities, eCooltra and Muving. As can be observed, these defined service areas are mainly located within the inner urban districts, which have a higher population density. The capital of Spain is a very interesting and active case study worldwide. In 2017, more than 1000 mopeds were implemented, and as of 2019, more than 6300 mopeds were running in Madrid, with a coverage area of around $50 \mathrm{~km}^{2}$. Nevertheless, the moped sharing market has not strongly accelerated its growth in the last years. Regarding Barcelona, there are ten operators offering moped sharing services that supply a large coverage area of around $40 \mathrm{~km}^{2}$. It was the pioneer city implementing shared mopeds services in Spain, with 250 mopeds in March 2016. Nowadays, over 8900 electric mopeds are available, representing the third city with the largest fleet implemented worldwide, after Bangalore and Taipei.

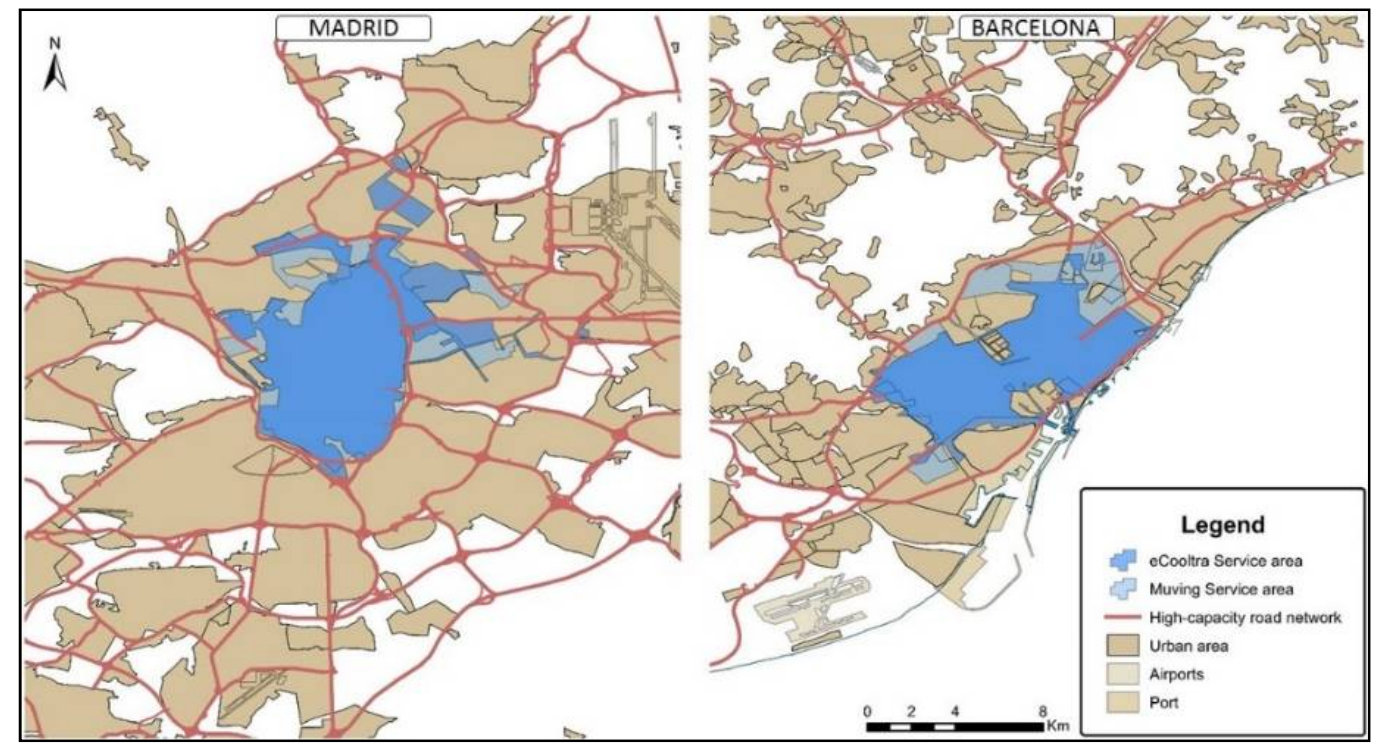

Figure 3. Service areas of two moped sharing companies operating in Madrid and Barcelona as of 2019.

\section{The Data: A Survey on Moped Sharing in Spanish Cities}

\subsection{Data Collection}

An online survey was conducted in order to investigate the attitudes and the main factors explaining the use of moped sharing. The web-based survey makes it possible to easily contact individuals using various transportation modes. In the case of moped sharing, this is complicated, since all existing moped sharing companies operate by using free-floating schemes. Web-based questionnaires also enable the interviewing of people who live in different cities, without many complications, in contrast to face-to-face surveys. Additionally, this approach has already been adopted in recent research on shared mobility services [41-43]. In these studies, the information collected includes an adequate level of heterogeneity, even though some sociodemographic statistics cannot be considered as fully representative of the whole population. 
The survey campaign was conducted from April to June 2018, and the questionnaire was specifically addressed to people living in those Spanish cities with the availability of moped sharing services (Madrid, Barcelona, Valencia, Zaragoza, Seville, Málaga, Murcia, Alicante, Granada, Cordova, and Cádiz). For this study, the online questionnaire was disseminated through social media, messaging apps, and on-street distribution of flyers, which included the web link of the survey. Despite the initial sample size being 505, the final database consisted of a sample of 430 valid responses (fully completed questionnaires received), due to missing values on relevant variables. For the further survey methodology applied, please refer to Monzon et al. [44]. Given the particular dates in which the survey campaign was conducted (springtime), and the main aim of the paper (capturing individuals' usage of shared mopeds), it should be noted that an increase in the use of moped sharing services may have probably been observed in those months, in comparison with other parts of the year, such as summer or winter.

The survey content is summarized in Table 1, and the individuals reported the following four main aspects: (i) general socioeconomic and demographic information, (ii) mobility-related variables, (iii) personal attitudes and preferences, and (iv) perceptions towards and use of shared mopeds. Please refer to Aguilera-García et al. [34] for further details on the questions addressed and the variables measured in this survey.

Table 1. Main aspects and variables measured in the questionnaire.

\begin{tabular}{ll}
\hline Aspects & Variables Measured \\
\hline General socioeconomic and demographic information & $\begin{array}{l}\text { Age, gender, occupation, net monthly income, level of education, } \\
\text { household structure, zip code }\end{array}$ \\
\hline Mobility-related variables & $\begin{array}{l}\text { Possession of a driving license and public transportation pass, vehicle } \\
\text { ownership, urban mobility patterns (trip frequency for different modes of } \\
\text { transport, number of trips) }\end{array}$ \\
\hline Personal attitudes and preferences & $\begin{array}{l}\text { Attitudes towards new technologies, decision factors concerning the } \\
\text { transport mode choice in urban trips, and perceptions towards the role of } \\
\text { vehicle ownership need in the future }\end{array}$ \\
\hline Perceptions towards and use of shared mopeds & $\begin{array}{l}\text { Adoption, frequency of use, intention to use a shared moped, decision } \\
\text { factors, trip purpose, travel time, aspects to be improved in current } \\
\text { moped sharing systems, main reasons for not using a shared moped }\end{array}$ \\
\hline
\end{tabular}

\subsection{Sample Description}

Sociodemographic characteristics and mobility-related attributes of the surveyed individuals are summarized in Table 2. The data collected include an adequate level of heterogeneity for the study conducted, and they are in line with the scientific studies on the use of shared mobility services from an online-based survey [41-43]. A preliminary analysis shows a lower presence of individuals aged above $35(28.2 \%)$ and females (32.5\%) in the sample. Furthermore, almost $35 \%$ of the individuals are students, with a substantial presence of employees $(38.9 \%)$. The income level is adequately distributed throughout the sample, although $30 \%$ of the respondents reported not having their own income or being dependent on family income. In relation to household structure, there is a significant share of families with children and people who share an apartment. Concerning residential location, respondents are heterogeneously distributed. Finally, the sample indicates a high technological penetration ( $98 \%$ of respondents use smartphones), which may be explained by the fact that this segment of the population would be more willing to respond to web-based surveys [43]. 
Table 2. Sociodemographic characteristics and travel-related characteristics of the sample (adapted from Aguilera-García et al. [34]).

\begin{tabular}{|c|c|c|c|}
\hline & Variables & Subgroup & Respondents (\% Sample) \\
\hline \multirow{24}{*}{$\begin{array}{l}\text { General socioeconomic and } \\
\text { demographic variables }\end{array}$} & \multirow{4}{*}{ Age } & From 18 to 25 & $204(47.5)$ \\
\hline & & From 26 to 34 & $105(24.3)$ \\
\hline & & From 35 to 49 & $77(17.9)$ \\
\hline & & Above 49 & $44(10.3)$ \\
\hline & \multirow[b]{2}{*}{ Gender } & Male & $290(67.5)$ \\
\hline & & Female & $140(32.5)$ \\
\hline & \multirow{4}{*}{ Occupation } & \multirow{4}{*}{$\begin{array}{l}\text { Employed } \\
\text { Student } \\
\text { Part-time employed/student } \\
\text { Unemployed, homemaker, or } \\
\text { retired }\end{array}$} & $167(38.9)$ \\
\hline & & & $149(34.6)$ \\
\hline & & & $103(23.9)$ \\
\hline & & & 11 (2.6) \\
\hline & \multirow{4}{*}{$\begin{array}{l}\text { Net monthly income } \\
\text { (personal) }\end{array}$} & Without own income & $128(29.8)$ \\
\hline & & Under 1000 Euro & $111(25.8)$ \\
\hline & & From 1000 to 2000 Euro & $109(25.3)$ \\
\hline & & Above 2000 Euro & $82(19.1)$ \\
\hline & \multirow{2}{*}{ Education } & University studies & $359(83.5)$ \\
\hline & & Non-university & $71(16.5)$ \\
\hline & \multirow{5}{*}{ Household structure } & Living alone & $30(6.9)$ \\
\hline & & Living with flatmates & $146(33.9)$ \\
\hline & & Couple without children & $63(14.6)$ \\
\hline & & Family with children below 24 & $173(40.3)$ \\
\hline & & Family with children above 25 & $18(4.3)$ \\
\hline & \multirow{2}{*}{ Place of residence } & City center & $233(54.1)$ \\
\hline & & Outskirts/suburbs & $197(45.9)$ \\
\hline & Smartphone & (Yes) & $421(97.9)$ \\
\hline \multirow{26}{*}{ Mobility-related variables } & \multirow{4}{*}{ Driving license } & Moped-less than $50 \mathrm{cc}$ & $169(39.3)$ \\
\hline & & Motorcycle-more than $50 \mathrm{cc}$ & $139(32.3)$ \\
\hline & & Car & $374(87.0)$ \\
\hline & & None of the above & $46(10.7)$ \\
\hline & Driving moto & (Yes) & $256(59.5)$ \\
\hline & \multirow{7}{*}{ Vehicle ownership } & \multirow{7}{*}{$\begin{array}{l}\text { Car ownership } \\
\text { Car availability } \\
\text { No car } \\
\text { Moped/motorcycle } \\
\text { ownership } \\
\text { Moped/motorcycle } \\
\text { availability } \\
\text { No moped/motorcycle }\end{array}$} & $188(43.7)$ \\
\hline & & & $121(28.1)$ \\
\hline & & & $121(28.1)$ \\
\hline & & & $63(14.7)$ \\
\hline & & & \\
\hline & & & $19(4.4)$ \\
\hline & & & 348 (80.9) \\
\hline & Public transportation pass & (Yes) & $335(77.9)$ \\
\hline & Ever used carsharing & (Yes) & $196(45.6)$ \\
\hline & Ever used moped sharing & (Yes) & $109(25.4)$ \\
\hline & Awareness of moped sharing & (Yes) & $335(77.9)$ \\
\hline & & Under 2 & $41(9.5)$ \\
\hline & Number of urban trips on a & From 2 to 3 & $226(52.6)$ \\
\hline & working day & From 4 to 5 & $128(29.8)$ \\
\hline & & Above 5 & $35(8.1)$ \\
\hline & & Under 2 & $118(27.4)$ \\
\hline & Number of urban trips on a & From 2 to 3 & $220(51.2)$ \\
\hline & non-working day & From 4 to 5 & $70(16.3)$ \\
\hline & & Above 5 & $22(5.1)$ \\
\hline & Vehicle ownership & It will not be a need & $278(64.6)$ \\
\hline & requirement in the future & It will remain a need & $152(35.4)$ \\
\hline
\end{tabular}

Concerning mobility-related characteristics, $89.3 \%$ of the respondents hold a driving license. Nevertheless, less than $60 \%$ of the individuals surveyed declared to know how to drive mopeds, which is essential to adopt moped sharing systems. In addition, there is a noticeable share of people with at least one vehicle in their household. As can be seen in 
Table 2, most of the respondents have a seasonal ticket or pass for public transportation $(77.9 \%)$. Concerning shared mobility adoption, almost half of the respondents have used carsharing services, while almost $72 \%$ of the respondents indicated their awareness of the existence of moped sharing systems, and approximately a quarter of the respondents have used this mobility option. Furthermore, the sample distribution shows slightly higher mobility rates during weekdays compared to weekends, with the respondents making 2-3 daily trips both on weekdays and weekends. Finally, it is interesting that $64.6 \%$ of the respondents opined that owning a vehicle will not be a need in the future. This reflects the trend to avoid ownership of assets in the field of urban transportation, in which e-moped sharing could play an important role.

The following other variables were requested, using the Likert five-point scale scoring system: (i) attitudes and preferences towards new technologies, and (ii) the importance of different decision factors concerning the transport mode choice in urban environments (see Tables 4 and 5 for further detail). Finally, the surveyed people were asked about their frequency of use of different urban transportation modes over a whole regular week. By weighing the data supplied by the respondents, a modal split has been calculated (see Figure 4) as the percentage of trips by mode over a whole typical week. This modal share mainly comprised active modes (34\%), public transit (28\%), and private vehicles (23\%). Other minority options include shared mobility options, taxi, and ridehailing. Overall, this represents the daily mobility patterns in Spanish urban areas fairly well (see, e.g., figures provided by the Metropolitan Mobility Observatory [45]).

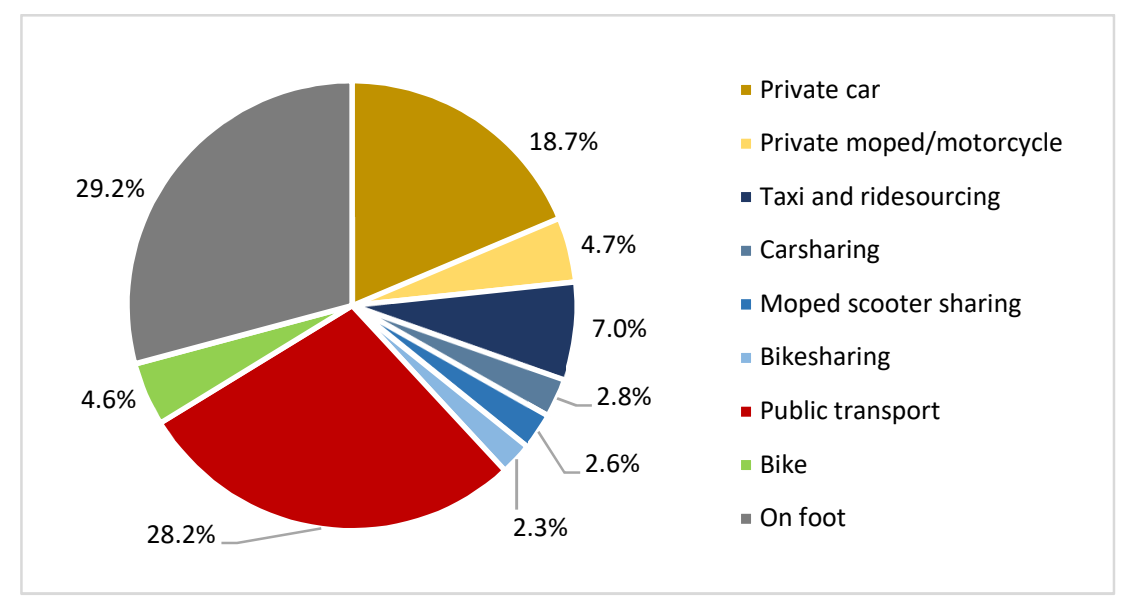

Figure 4. Modal split (\% of trips by mode over a whole typical week) of the total sample.

\section{Methodology}

Statistical analysis has been conducted to explore the relationship between multiple variables collected in the questionnaire. Different techniques have been adopted, namely, the non-parametric Kruskal-Wallis test, analysis of variance (ANOVA), and post hoc tests with Bonferroni adjustment. First, a Kruskal-Wallis test framework was conducted to determine whether sociodemographic and travel-related characteristics were statistically different across non-users, occasional users, and frequent users of shared mopeds. This analysis allowed us to identify statically significant differences between these categories of individuals. Analysis of variance (ANOVA) and post hoc tests with Bonferroni adjustment were conducted to check statistical mean differences in specific variables concerning moped sharing usage. Finally, two binary logit models have been conducted to (i) analyze the key factors determining the potential use of shared mopeds, and (ii) explore individuals' opinions on whether owning a private vehicle will not be a need in the future. In this respect, respondents were asked whether they would consider using this mobility alternative in the future and whether they consider that owning a private vehicle will remain a need in the future. These two answers represent the dependent variables of the binary choice models. 
Logit regressions fall into the category of utility maximization models, and they incorporate the microeconomic theory of consumer choice behavior [46]. According to the utility theory, the individual will choose the option (in our case, the potential use of moped sharing, and the opinion towards whether owning a private vehicle will not be a need in the future) with the highest utility. Each choice is determined by the observed socioeconomic and demographic information of the individual (I), mobility-related attributes (M), and personal attitudes and preferences (A). Then, the utility in the model is approached as follows:

$$
U_{\text {in }}=f\left(I_{\text {in }}, M_{\text {in }}, A_{\text {in }}\right),
$$

where $U_{i n}$ is the utility gained by individual $\mathrm{n}$ for choosing alternative $i . U_{i n}$ is considered a random variable and therefore consists of a sum of observed variables $V_{\text {in }}$-a systematic or representative component of the utility—and random components $\varepsilon_{i n}$, as follows:

$$
U_{i n}=V_{i n}+\varepsilon_{i n}=\sum \beta_{n} X_{i n}+\varepsilon_{i n},
$$

where $X_{i n}$ is a vector of measurable characteristics that define utility, and $\beta_{n}$ is a vector of coefficients to be estimated. Economic theory assumes that the individual $n$ will choose the option with the highest utility. As explained by Ben-Akiva and Lerman [46], the probability that the respondent $\mathrm{n}$ will choose an alternative $i$ can be expressed as follows:

$$
P_{i}=\frac{e^{V_{i n}}}{\sum_{j} e^{V_{i j}}} .
$$

Logit models are widely known in the scientific literature, and a detailed description of the logit model is beyond the scope of this paper. For further details, the reader is referred to Ben-Akiva and Lerman [46], or Ortúzar and Willumsen [47], among others.

\section{Results and Discussion}

The results obtained from the analysis conducted in this research are summarized in this section. First, Section 6.1 explores the main socioeconomic and travel-related characteristics influencing moped sharing usage. Then, Section 6.2 shows the attitudes and perceptions of moped sharing services by both users and non-users. The role that moped sharing may play in reducing vehicle ownership in the future is explored in Section 6.3. Finally, the modeling results from the logit model exploring the key drivers determining the potential use of moped sharing, and the potential role of shared mopeds in reducing vehicle ownership, are shown in Section 6.4.

\subsection{Assessment of Sociodemographic and Travel-Related Characteristics on Moped Sharing Usage}

This section highlights some findings on the relationship between sociodemographic information and mobility patterns on moped sharing usage. To that end, the respondents have been grouped as follows, in terms of their use of shared mopeds: (i) non-users of moped sharing systems $(n=321)$; (ii) occasional users $(n=70)$, that is, people using shared mopeds less than once per week; and (iii) frequent users $(n=39)$, that is, people using shared mopeds once per week or above. A quarter of the total respondents (25.3\%) declared to have ridden a shared moped. With respect to non-users of moped sharing systems, it is noteworthy that around half of them would consider riding a shared moped in the future. A Kruskal-Wallis test was conducted to determine whether sociodemographic and travel-related characteristics were different across frequent users, occasional users, and non-users of shared mopeds (see Table 3). For further details regarding the potential use of moped sharing by current non-users, see Section 6.4. 
Table 3. Sociodemographic and travel-related characteristics concerning the use of shared mopeds (\% of the surveyed people in each category) and Kruskal-Wallis test results (adapted from AguileraGarcía et al. [34]).

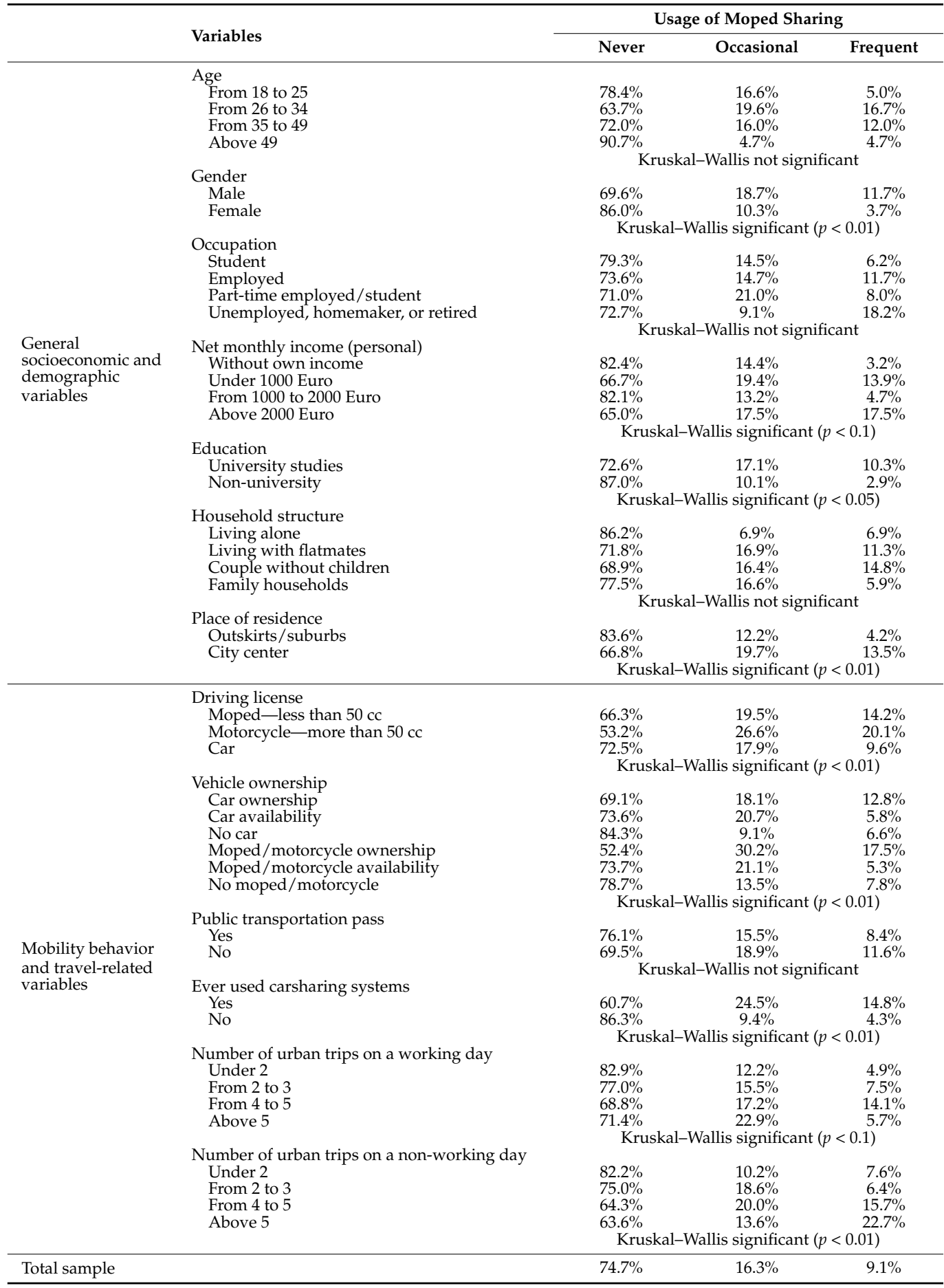

As can be observed in Table 3, the results indicate a significantly ( $p$-value $<0.01$ ) higher percentage of males $(30.4 \%)$ in the sample having ever used moped sharing, compared to $14.0 \%$ of females. Additionally, no statistically significant differences have been found regarding age, which could be due to the higher presence of individuals aged under 34 in the sample. Nevertheless, people aged from 26 to 34 present a higher penetration of moped sharing (34.3\% of people in this age segment), while much lower values are observed for other age segments of the sample. The proportion of frequent users-that is, people using 
moped sharing at least once per week-is particularly relevant in this segment of age $(16.7 \%)$. This is worth noting, since young adults become more familiar with emerging technologies, which is a key driver when adopting a shared mobility option. As can be noted, the percentage of people having used moped sharing is not negligible for people aged between 35 and $49(28.0 \%)$. This seems reasonable given that, at least in the case of Spain, moped sharing is also penetrating above middle-aged adults. Furthermore, age seems to be among the main reasons behind the greatest adoption of moped sharing in some household structures, particularly those respondents sharing a household and the couples without children.

Concerning the level of education, individuals with higher education present a significantly ( $p$-value $<0.05$ ) higher proportion of users of this mobility alternative; this is shown by the $27.4 \%$ of respondents with university studies who declared to have used moped sharing, while this percentage is significantly lower among those people without university studies (13.0\%). These findings are in line with previous research about other shared mobility alternatives $[13,22,30]$, and may be explained by the faster tendency to become more familiar with innovative services and technological advances among highly educated individuals. As for residential location, we can see that this variable significantly influences the adoption of moped sharing, as $33.2 \%$ of the respondents living in city centers have used moped sharing at least once, which contrasts with a lower penetration among people living in the outskirts $(16.4 \%)$. This seems reasonable given that city centers are the areas usually served by operators and consequently have a higher supply of shared mopeds. Finally, findings regarding the level of income do not present clear trends and only provide statistically significant results at the $10 \%$ level.

Table 3 also includes some trends concerning mobility-related characteristics. As seems reasonable, a significantly $(p$-value $<0.01)$ higher proportion of individuals with a driving license have adopted moped sharing. Similarly, those individuals that declared to own a vehicle show a significantly ( $p$-value $<0.01$ ) higher probability of having adopted moped sharing, while only around $20 \%$ of the respondents not owning a private car/moto declared to have adopted moped sharing services. This finding may be somehow surprising given that owning a private vehicle would promote discarding/disregarding other alternative modes. Furthermore, a higher proportion of respondents without a public transportation pass $(31.5 \%)$ have declared themselves as users of moped sharing. This result may indicate that this shared mobility mode captures demand from public transit. Nevertheless, this effect was not found statistically significant.

According to the Kruskal-Wallis test, the familiarity of individuals with other shared mobility modes significantly influences their moped sharing adoption. In this respect, a high proportion of respondents having used carsharing services (39.3\%) declared to have used moped sharing. This percentage is significantly reduced for those people not having ever used other shared modes (13.7\%). Table 3 also shows a statistically significant ( $p$-value $<0.01)$ variation in trip frequency during weekdays and non-working days across non-users, occasional users, and frequent users of shared mopeds. Regarding mobility patterns on working days, users of shared mopeds are noticeably lower among people making less than two trips per day $(17.1 \%)$ when compared with respondents making more than three trips per day (around 30\%). This trend is also observed for mobility on non-working days, since, e.g., the proportion of moped sharing users among people making more than three trips per day (around 36\%) almost double the figures among people making less than two trips per day $(17.8 \%)$.

The respondents also reported, in the survey, (i) their preferences and attitudes towards new technologies, and (ii) the importance they give to different decision factors concerning the transport mode choice in urban environments. We can use this data to explore the relationship between the use of moped sharing and these variables. To that end, we conducted an analysis of variance (ANOVA) and post hoc tests with Bonferroni adjustment to check the statistical differences between the means of personal attitudes and trip factors appraisal of non-users, occasional users, and frequent users (see Tables 4 and 5). 
The results of the Bonferroni test are presented in Table 5, including the differences between the means and the Bonferroni-adjusted significance of the difference.

Table 4. Mean and standard deviation of attitudes and trip factors appraisal of non-users, occasional users, and frequent users of shared mopeds.

\begin{tabular}{|c|c|c|c|c|c|c|}
\hline \multirow{3}{*}{ Personal Attitudes and Trip Factors Appraisal } & \multicolumn{6}{|c|}{ Usage of Moped Sharing } \\
\hline & \multicolumn{2}{|c|}{ Never } & \multicolumn{2}{|c|}{ Occasional } & \multicolumn{2}{|c|}{ Frequent } \\
\hline & Mean & Std. Dev & Mean & Std. Dev & Mean & Std. Dev \\
\hline \multicolumn{7}{|c|}{ Personal attitudes and preferences towards new technologies } \\
\hline Download new apps & 3.445 & 1.033 & 3.857 & 0.921 & 3.949 & 1.356 \\
\hline Share personal data & 2.882 & 1.139 & 3.286 & 1.079 & 3.538 & 1.211 \\
\hline Share bank account info & 2.794 & 1.212 & 3.371 & 1.106 & 3.795 & 1.174 \\
\hline \multicolumn{7}{|c|}{ Decision factors concerning transport mode choice in urban environments } \\
\hline Price & 4.078 & 1.111 & 4.357 & 0.869 & 3.872 & 1.031 \\
\hline Parking availability & 3.944 & 1.305 & 4.286 & 1.009 & 4.564 & 0.552 \\
\hline Travel time & 4.196 & 0.946 & 4.214 & 0.832 & 4.256 & 0.751 \\
\hline Travel time reliability & 3.994 & 0.952 & 4.000 & 0.917 & 3.949 & 0.916 \\
\hline Frequency & 4.271 & 0.869 & 4.214 & 0.740 & 4.205 & 0.801 \\
\hline Proximity to real origin/destination & 4.199 & 0.900 & 4.043 & 0.892 & 4.205 & 0.801 \\
\hline Comfort & 3.729 & 1.060 & 3.843 & 0.987 & 3.949 & 0.999 \\
\hline Environmental awareness & 3.302 & 1.265 & 3.071 & 1.196 & 3.897 & 1.231 \\
\hline Not having to drive & 2.514 & 1.434 & 2.171 & 1.262 & 2.000 & 1.214 \\
\hline Ability to carry people & 2.857 & 1.306 & 3.043 & 1.221 & 3.051 & 1.169 \\
\hline Luggage & 3.184 & 1.173 & 3.129 & 1.076 & 3.000 & 1.100 \\
\hline Safety & 3.801 & 1.111 & 3.686 & 1.029 & 3.718 & 0.944 \\
\hline
\end{tabular}

Table 5. Differences between the means of personal attitudes and trip factors appraisal of nonusers, occasional users, and frequent users of shared mopeds. Results of the Bonferroni multiplecomparison test.

\begin{tabular}{|c|c|c|c|c|c|}
\hline \multirow{3}{*}{ Personal Attitudes and Trip Factors Appraisal } & \multirow{3}{*}{ Col Mean } & \multicolumn{4}{|c|}{ Row Mean } \\
\hline & & \multicolumn{2}{|c|}{ Never } & \multicolumn{2}{|c|}{ Occasional } \\
\hline & & Diff. & $p$-Value & Diff. & $p$-Value \\
\hline \multirow[t]{2}{*}{ Download new apps } & Occasional & 0.412 & 0.009 & & \\
\hline & Frequent & 0.503 & 0.015 & 0.092 & 1.000 \\
\hline \multirow[t]{2}{*}{ Share personal data } & Occasional & 0.404 & 0.022 & & \\
\hline & Frequent & 0.657 & 0.002 & 0.253 & 0.799 \\
\hline \multirow[t]{2}{*}{ Share bank account info } & Occasional & 0.577 & 0.001 & & \\
\hline & Frequent & 1.000 & 0.000 & 0.423 & 0.229 \\
\hline \multirow[t]{2}{*}{ Price } & Occasional & 0.279 & 0.145 & & \\
\hline & Frequent & -0.206 & 0.768 & -0.485 & 0.071 \\
\hline \multirow{2}{*}{ Parking availability } & Occasional & 0.342 & 0.099 & & \\
\hline & Frequent & 0.620 & 0.008 & 0.278 & 0.753 \\
\hline \multirow[t]{2}{*}{ Travel time } & Occasional & 0.018 & 1.000 & & \\
\hline & Frequent & 0.060 & 1.000 & 0.042 & 1.000 \\
\hline \multirow[t]{2}{*}{ Travel time reliability } & Occasional & 0.006 & 1.000 & & \\
\hline & Frequent & -0.045 & 1.000 & -0.051 & 1.000 \\
\hline \multirow{2}{*}{ Frequency } & Occasional & -0.057 & 1.000 & & \\
\hline & Frequent & -0.066 & 1.000 & -0.009 & 1.000 \\
\hline \multirow[t]{2}{*}{ Proximity to real origin/destination } & Occasional & -0.157 & 0.550 & & \\
\hline & Frequent & 0.006 & 1.000 & 0.162 & 1.000 \\
\hline \multirow[t]{2}{*}{ Comfort } & Occasional & 0.114 & 1.000 & & \\
\hline & Frequent & 0.220 & 0.644 & 0.106 & 1.000 \\
\hline \multirow[t]{2}{*}{ Environmental awareness } & Occasional & -0.231 & 0.488 & & \\
\hline & Frequent & 0.595 & 0.016 & 0.826 & 0.003 \\
\hline \multirow[t]{2}{*}{ Not having to drive } & Occasional & -0.343 & 0.187 & & \\
\hline & Frequent & -0.514 & 0.089 & -0.171 & 1.000 \\
\hline \multirow[t]{2}{*}{ To carry people } & Occasional & 0.186 & 0.813 & & \\
\hline & Frequent & 0.195 & 1.000 & 0.008 & 1.000 \\
\hline \multirow{2}{*}{ Luggage } & Occasional & -0.055 & 1.000 & & \\
\hline & Frequent & -0.184 & 1.000 & -0.129 & 1.000 \\
\hline \multirow[t]{2}{*}{ Safety } & Occasional & -0.115 & 1.000 & & \\
\hline & Frequent & -0.083 & 1.000 & 0.032 & 1.000 \\
\hline
\end{tabular}


In light of the Bonferroni multiple-comparison test, the results show that personal attitudes and preferences towards new technologies had a significant ( $p$-values $<0.05)$ mean difference when comparing the use of moped sharing. As expected, the results indicate that those individuals feeling fairly comfortable with testing, downloading, and using new mobile services and applications, as well as willing to share bank account information and any personal data via smartphone, tend to use moped sharing more intensively (see Tables 4 and 5).

Regarding the decision factors most highly appreciated by the respondents when choosing an urban mobility option, parking availability and environmental awareness were decision factors with a significant mean difference when comparing non-users, occasional users, and frequent users (Bonferroni-adjusted significance tests with $p$-values < 0.05). First, for the frequent users, there was a higher significant mean difference in parking availability (mean difference $=0.620, p$-value $=0.008$ ), when compared to non-users. This could be related to the benefit of moped sharing concerning on-street parking. At least in Spain, e-mopeds are not subject to on-street parking fees, therefore these vehicles can be easily dropped off by users at the end of their trip. Second, frequent users present a higher environmental consciousness (see Table 5) when choosing an urban transport mode, since there was a higher significant mean difference when compared to non-users (mean difference $=0.595, p$-value $=0.016$ ) and occasional users (mean difference $=0.826$, $p$-value $=0.003$ ). Again, this makes sense, since all the shared mopeds or motorcycles are fully electric in Spain, thus contributing to air pollution reduction and promoting more sustainable urban transport.

Figure 5 shows the distribution of urban modal split during a whole typical week for each group of users of moped sharing. ANOVA and post hoc tests with Bonferroni adjustment were also conducted, and noticeable differences can be observed in some cases. The non-users of moped sharing show a more intense use of the private car (19.8\%) compared to occasional (17.4\%) and especially frequent users of moped sharing (13.1\%), although no statistically significant differences have been found. Given that shared mopeds are fully electric in most countries, promoting moped sharing would improve air quality in urban areas. Likewise, as long as private vehicles are partly replaced by shared mobility systems, the current conditions regarding road congestion, air pollution, noise, and scarcity of public space in urban areas would be improved.

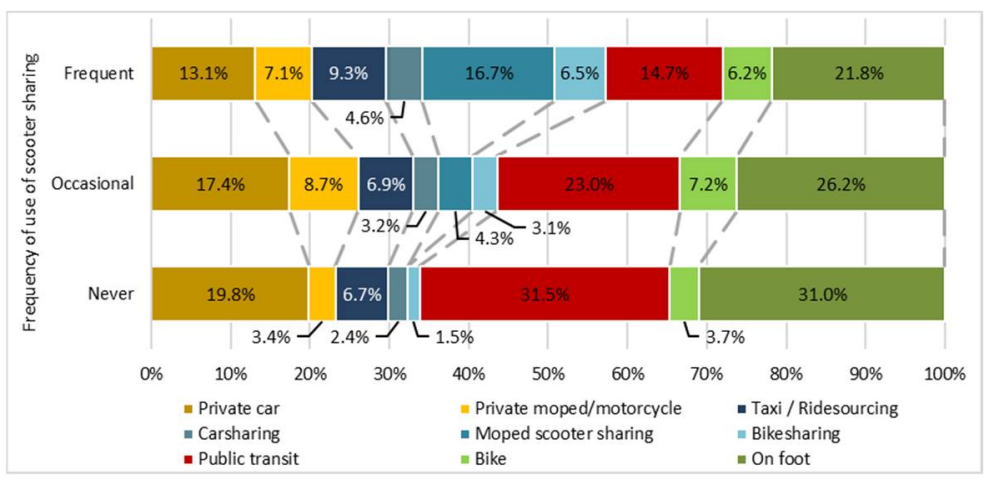

Figure 5. Modal split by frequency of use of moped sharing (\% of trips by mode over a whole typical week).

Otherwise, moped sharing users present a lower use of public transport and active modes compared to non-users. Furthermore, a one-way ANOVA confirmed that there were significant differences ( $p$-values $<0.05$ ) concerning the use of public transport across non-users and users of shared mopeds. Therefore, the net effect of moped sharing on urban mobility seems to be somehow unclear in its current form of implementation. Nevertheless, the potential benefits of moped sharing to urban sustainability (e.g., by reducing the use of the private vehicle) should move policymakers to promote its use within an integrated mobility supply, together with public transport modes. 
Concerning shared mobility, we can observe that on-demand mobility and shared vehicles are used more frequently by moped sharing users, especially frequent users (37.1\%). Additionally, significant differences $(p$-values $<0.05)$ between non-users, occasional users, and frequent users have been found when using a one-way ANOVA for the use of carsharing, bikesharing, and ridesourcing. This suggests that moped sharing may complement other shared mobility options, such as carsharing or bikesharing, which constitute more sustainable mobility alternatives compared to the private car. It should also be noted that these shared mobility systems can be an attractive transport option under policy scenarios of restricting the use of private cars in urban areas.

\subsection{Insights on the Use of Moped Sharing Systems}

\subsubsection{Moped Sharing Adoption, Use, and Impact on Travel Behavior}

The respondents who expressed having used moped sharing services (both occasional and frequent users, $n=109$ ) reported their mobility-related patterns concerning the use of this transport mode, particularly the trip purpose, typical travel time, reasons for choosing shared mopeds, evaluation of current services, etc. This provides an interesting panorama for operators and transport planners when designing actions to promote this shared mobility option.

The trip purposes for the moped sharing trips reported in this subsample are shown in Figure 6. As can be observed, leisure activities are the most common trip purpose in the sample, since almost $64 \%$ of the users reported that they occasionally or frequently ride a shared moped for this purpose. Additionally, moped sharing users considered these systems an attractive mobility option to move around the inner urban districts and areas with restrictions on the use of private cars (frequently and occasionally used by $56.4 \%$ of the respondents). It can also be observed that $17 \%$ of the moped sharing users reported using frequently shared mopeds when commuting. According to this result, it appears that individuals who commute by moped sharing systems may become frequent users, which seems evident, since commuting represents a daily forced activity. This, together with the possible substitution effect between private vehicles and shared moped use, and the attractiveness of these new services under policy scenarios of restricting the use of private cars in urban areas, can make moped sharing an interesting alternative when traveling in urban environments.

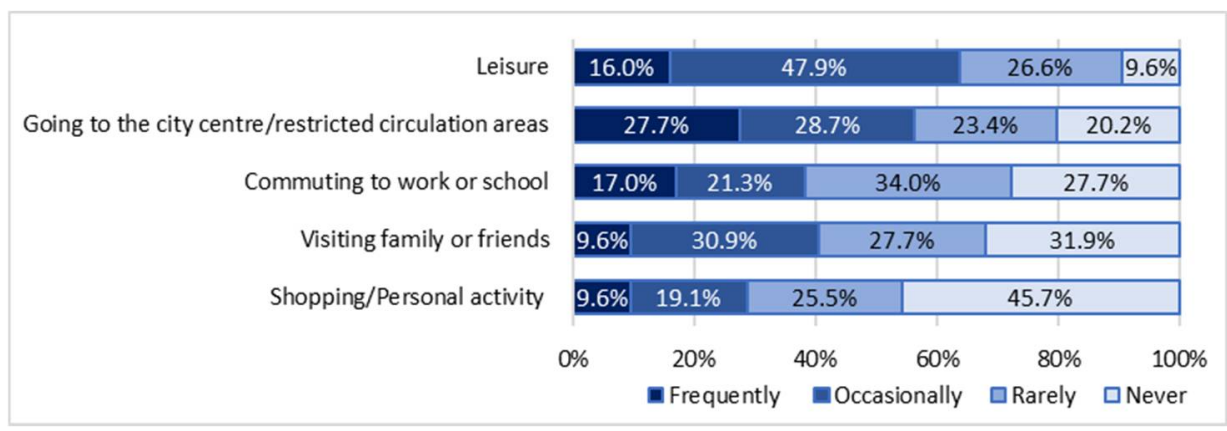

Figure 6. Distribution of the trip purpose.

In addition, Figure 7 shows the distribution of the main reasons for using these mobility services. The benefits of easily parking the moped/motorcycle (54.3\%), along with the flexibility to drive in urban environments $(52.1 \%)$, were contemplated as the most important arguments for choosing this mobility option. Again, moped sharing seems to be particularly attractive when (i) traveling around urban areas, avoiding road congestion and driving easily through narrow streets, and (ii) parking, since e-mopeds are not subject to parking fees in Spain. Moped sharing users also highlight the good performance of these new services and their competitive price. It is worth noting that not having a private vehicle available was considered the main reason by only a minority of users $(4.3 \%)$, probably 
because they are aware of the following many other transport alternatives available in the city: public transit, other shared mobility services (bikesharing, carsharing), etc.

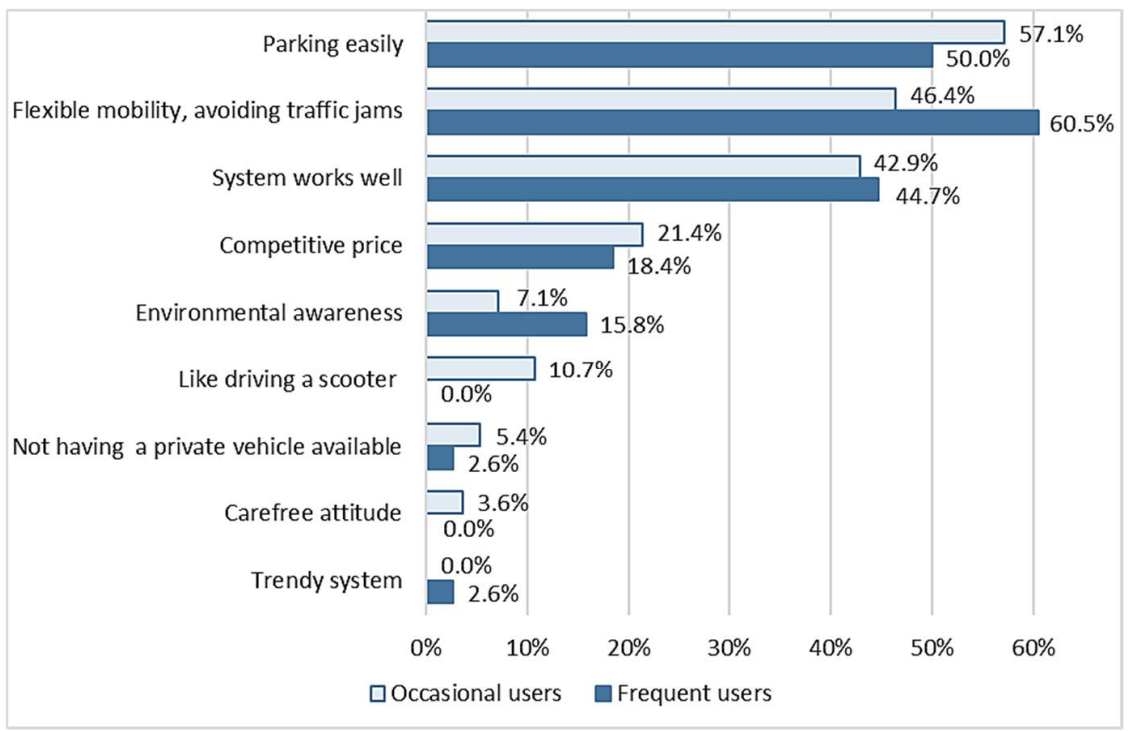

Figure 7. Distribution of main reasons for using moped sharing—respondents could indicate two at the most.

The survey collected further mobility patterns. For instance, most moped sharing users reported traveling alone by shared moped (70.6\%). As shown in Figure 8, many users indicated that their travel time by shared e-moped is 10-15 min (50\%). Most of them $(84.3 \%)$ reported that they would walk less than $500 \mathrm{~m}$ to pick up an e-moped, and nearly half of the users are not willing to walk beyond $200 \mathrm{~m}$. Furthermore, there does not seem to be clear differences between occasional and frequent users on these variables. In fact, a one-way ANOVA confirmed that there were no significant differences between the responses of occasional and frequent users, neither for the average travel time of trips made nor for the typical distances willing to walk to pick up a shared moped.

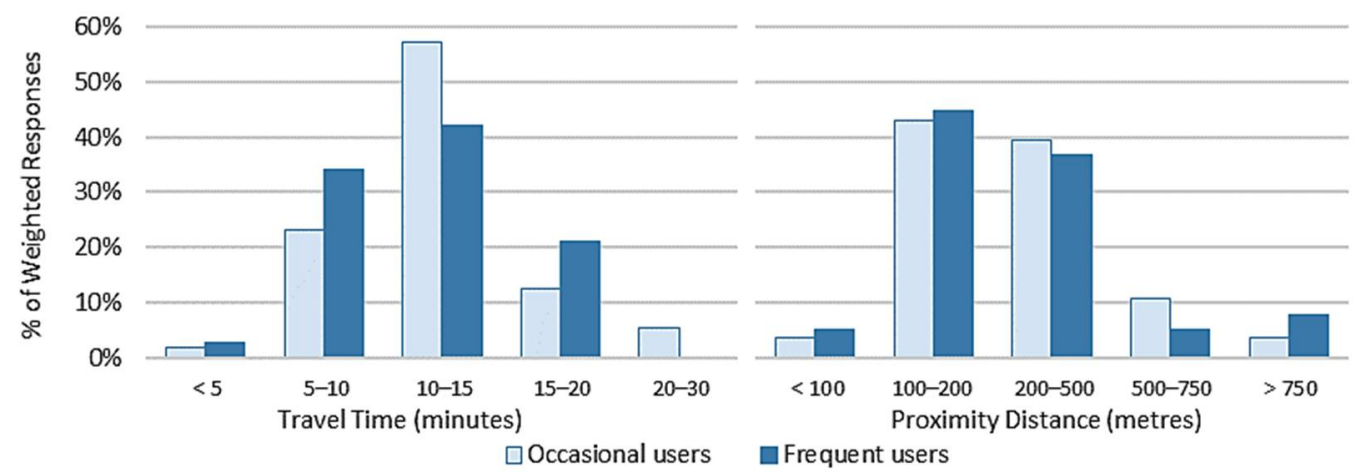

Figure 8. Average travel time of trips made in moped sharing, and typical distance willing to walk to pick up a shared moped.

Further insight can be provided from the data collected, since the moped sharing users reported on the previous transportation option they used to choose for the trips currently made by moped sharing (see Figure 9). This question is intended to inform about the modal shifts experienced in urban mobility due to the implementation of moped sharing. As can be observed, moped sharing has partly replaced public transit, mostly among occasional users $(55.4 \%)$. However, $26.3 \%$ of the frequent users of moped sharing in the sample previously chose the private vehicle for these trips. Therefore, the effect of moped sharing 
on urban sustainability is somehow ambiguous given the opposite effects observed on the previous use of public transit and private vehicles. Again, a one-way ANOVA showed that there were no significant differences between the responses of occasional and frequent users of shared e-mopeds.

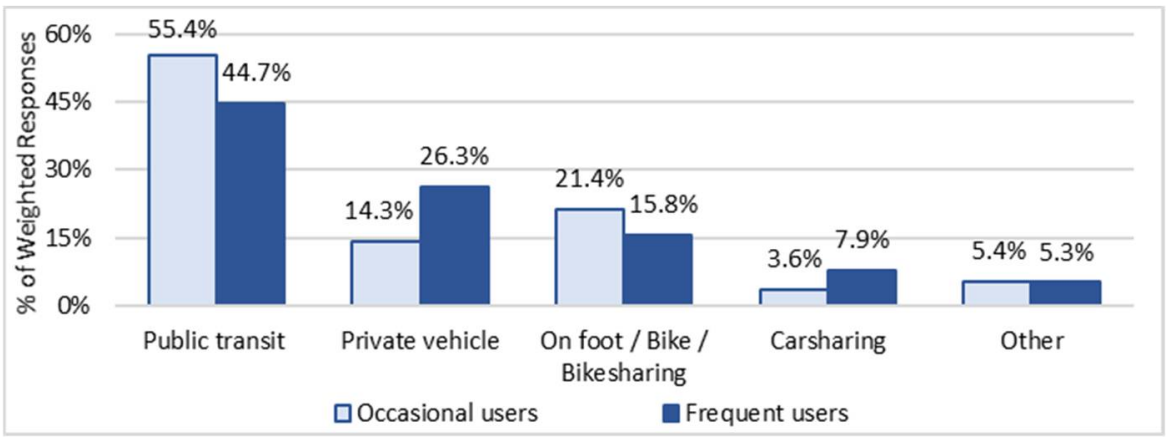

Figure 9. Main transportation mode previously used to make current trips by moped sharing.

In order to investigate the decisive factors determining the choice of shared mopeds in urban trips instead of public transit, moped sharing users were asked about the main aspects motivating their choice. It was found that $77 \%$ of those who shifted from transit highlighted travel time saving as the main reason, followed by increased proximity to the origin or destination (35\%) provided by shared mopeds. Therefore, moped sharing is perceived as a new mobility option that increases the flexibility, accessibility, and attractiveness provided by public transit services with fixed routes and schedules. Therefore, moped sharing users might leave public transit (at least occasionally) to this new transport mode. Moped sharing users could also use a shared moped to overcome the last-mile problem, being able to foster sustainable modal interchange. Again, it highlights the importance of integrating moped sharing systems with public transport, in order to promote their complementary use through intermodal trips, in such a way that, e.g., moped sharing would act as a feeder for the public transit network in areas with lower transit accessibility. This may partly discourage the use of private vehicles, contributing to tackling the problems of scarcity of public space and road congestion generally experienced in city centers, and consequently moving urban mobility towards sustainability.

Finally, moped sharing users were asked about the aspects to be improved in these systems. According to Figure 10, reducing current prices (58.5\%) and expanding the current area served (53.2\%) were reported as the main priorities among moped sharing users. Approximately one-third of the users also mentioned the need to increase the current fleet $(33.0 \%)$. Given the potential benefits to urban livability of a higher implementation of shared e-mopeds, local governments should consider promoting the extension of these services to areas outside the central districts. Nevertheless, as previously mentioned, expanding the area served is particularly critical in large metropolitan areas, and e-mopeds are less competitive in suburban environments due to, e.g., their lower speed.

Occasional and frequent users seem to have different points of view regarding the aspects that they consider should be improved, although no statistically significant differences have been found between both categories. On the one hand, occasional users are particularly interested in the general aspects of the system, such as improving mobile app characteristics and simplifying the drop-in process. By contrast, frequent users have already assumed the basic functioning of moped sharing services and are more focused on specific operating issues. These individuals reported being more concerned about improving fleet characteristics (batteries, top speed, power, braking system, cleaning, etc.) and helmet-related issues (having enough disposable hygienic caps, having a second helmet, etc.). 


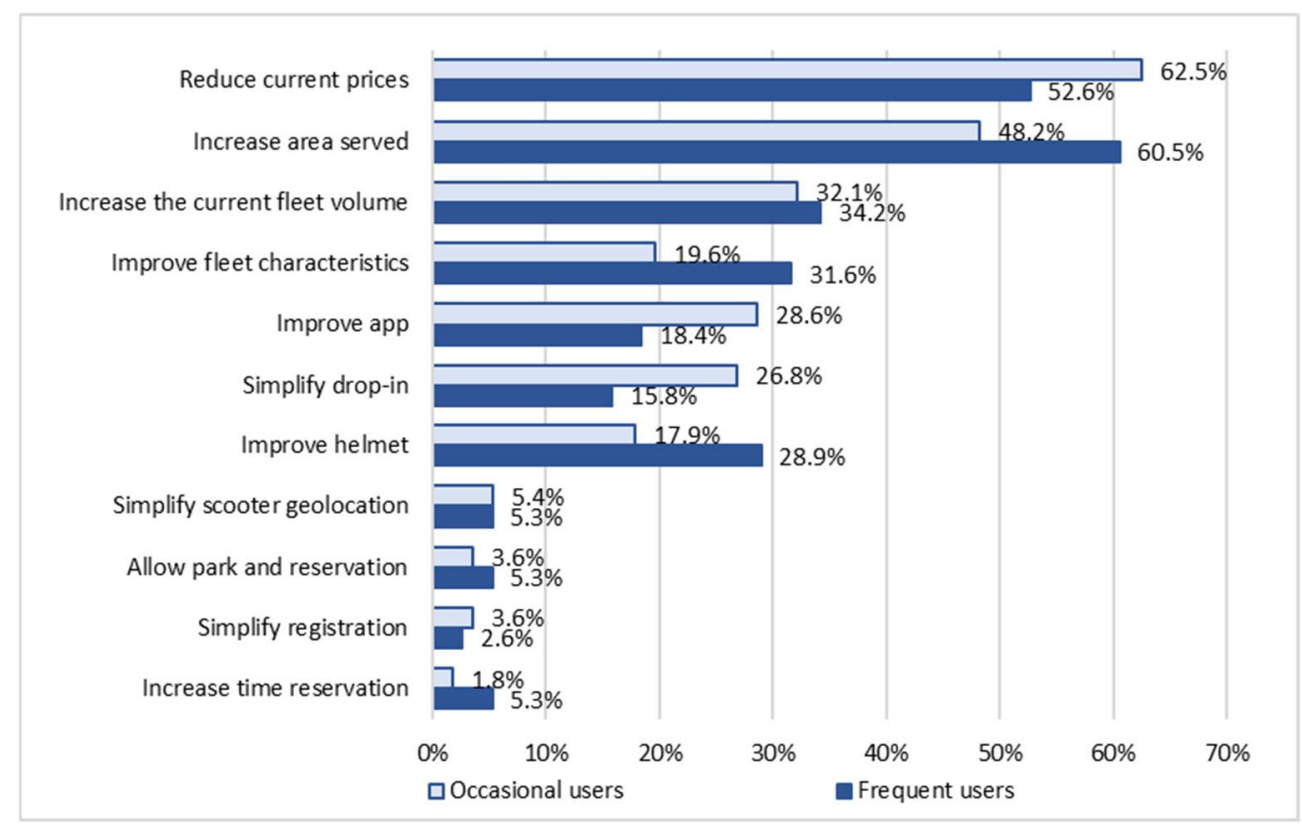

Figure 10. Aspects to be improved in moped sharing systems (\% of affirmative responses-the respondents could indicate three at most).

\subsubsection{Perceptions of Non-Users of Moped Sharing}

In this section, we highlight some findings regarding non-users of moped sharing services, which represent the majority of the sample $(n=321)$. These individuals were asked whether they would consider using this mobility alternative in the future. This information allowed us to divide these respondents into the following two main groups: (i) non-potential users of moped sharing systems, that is, those respondents that declared neither having ever used moped sharing services nor considering their use in the future; and (ii) potential users, that is, those that declared not having ever used a shared moped, but consider its use in the future. It is worth noting that around half of the non-users $(46.6 \%)$ would consider using this mobility alternative in the future. Furthermore, a one-way ANOVA confirmed that there were slightly significant differences between the responses of non-potential and potential users of moped sharing.

The distribution of the main reasons for not using shared mopeds can be observed in Figure 11. This is of special interest to moped sharing operators and transport planners to promote this shared mobility option. As can be observed, the main barriers are related to the scarce familiarity with riding motorcycles/mopeds, or even not knowing how to ride them, which is essential to adopt moped sharing systems. Most of the non-users $(71.5 \%)$ reported having driven mopeds very rarely as the most important reason for not choosing this mobility option. This is followed by the perception of the danger of driving a motorcycle, moped, and Vespa-like vehicle in urban areas, a feeling that tends to be more intense among people not driving motorcycles/mopeds. Some statically valid differences ( $p$-value $<0.05)$ are found across non-users, since a higher percentage concerned about this issue is observed among non-potential users $(30.2 \%)$, compared with potential users $(13.6 \%)$. The unawareness of moped sharing systems and car-prone attitudes were also cited among the most important reasons for not choosing this mobility alternative. This may indicate that the main barrier, in both potential and non-potential users, would be linked to having a first experience with a shared moped. This problem could be overcome by, e.g., providing a trial period, which would allow people to adopt this mobility option at a low cost. Further aspects that could be managed by operators, as is the case of prices, registration process or the area served, were not perceived as the main reasons for not adopting moped sharing. 


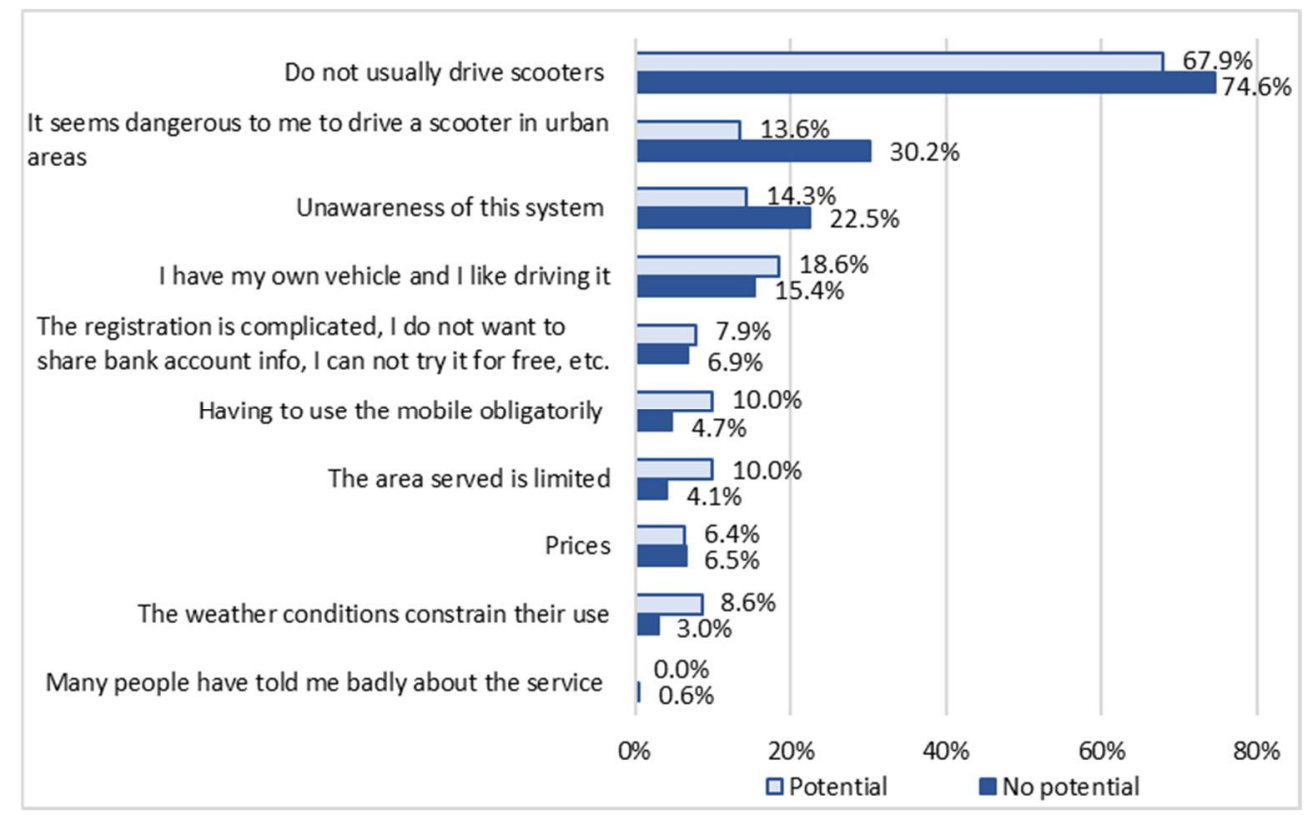

Figure 11. Distribution of main reasons for not using moped sharing ( $\%$ of affirmative responses-the respondents could indicate three at the most).

\subsection{Potential Relationship in Reducing Vehicle Ownership Need}

Moped sharing is a new alternative of urban transport that increases accessibility and mobility supply, and theoretically could decrease the existing fleet of conventional combustion engine vehicles by impacting on private vehicle ownership decisions. In the questionnaire, the respondents were asked whether they consider that owning a private vehicle will remain a need in the future. In this section, we explore how the implementation of shared mopeds could influence individuals' perceptions of the need for owning a private vehicle. After this preliminary overview, a binomial logit specification has been developed to deeply explore the key drivers determining individuals' opinions on whether owning a private vehicle will not be a need in the future (see Model 2 in the next Section 6.4).

Figure 12 shows the distribution of answers according to the type of user of moped sharing services. As mentioned above (see Table 2), $64.6 \%$ of the total respondents declared that vehicle ownership will no longer be a necessity in the future. Nevertheless, non-users of moped sharing seem to be more skeptical about private vehicle relinquishment in the future, according to Figure 12. Furthermore, a one-way ANOVA confirmed that there were significant differences between the responses of non-users and users of moped sharing.

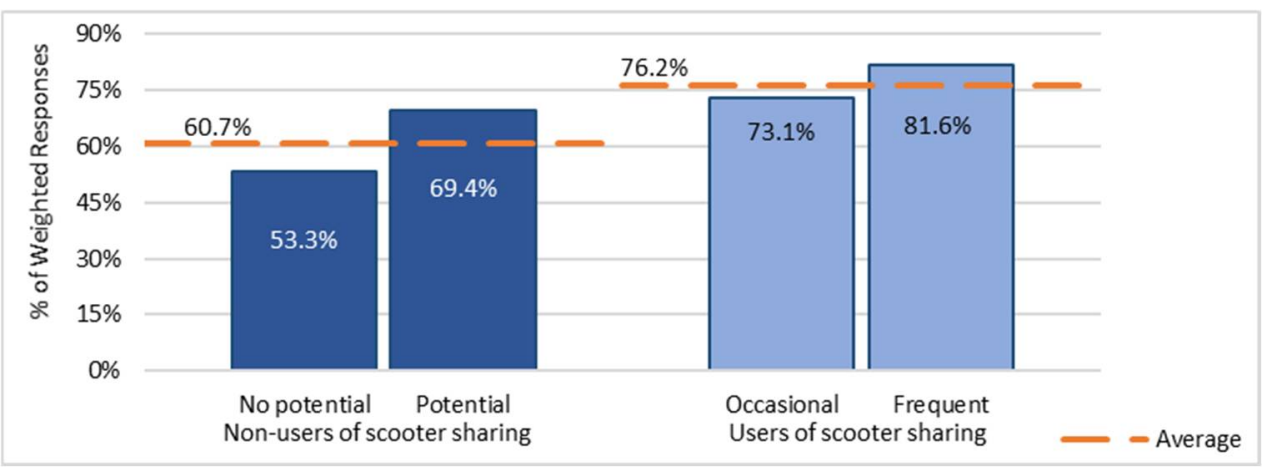

Figure 12. Individuals' opinions on whether owning a private vehicle will not be a need in the future (\% of affirmative responses).

A significantly higher proportion of people not concerned about owning a vehicle in the future was observed among users of moped sharing $(76.2 \%)$, and particularly among 
frequent users $(81.6 \%)$. As discussed, moped sharing could play a role in reducing vehicle ownership, by providing extra accessibility when public transit does not meet the riders' needs. This may encourage, at least some users, not to own a private vehicle. This finding may apply to users of other shared mobility modes, e.g., carsharing.

Furthermore, statistically significant differences have been found between potential and non-potential users of shared mopeds ( $p$-value $<0.05$ ), since a higher proportion of potential users $(69.4 \%)$ believe that vehicle ownership will not be a requirement in the future, compared to non-potential users (53.3\%). Regarding potential moped sharing users, this trend is relevant because they perceive that these services can increase transportation opportunities and may impact on reducing vehicle ownership rates in cities in the coming years.

In conclusion, moped sharing may capture modal share from private cars in the future, and this would bring important benefits to urban livability and sustainability, as has been mentioned above. Reducing private vehicle ownership may have positive effects on the demand for alternative urban modes, e.g., public transit. This fact should be considered together with other findings in opposition, previously noted above, such as some modal shares captured by e-mopeds from public transit, when evaluating the effect of wider adoption of moped sharing on urban sustainability.

\subsection{Modeling Results and Discussion}

The results from two logit models exploring, including (i) the key drivers determining the willingness to use moped sharing (Model $1 ; n=321$ ), and ii) individuals' opinions on whether owning a private vehicle will not be a need in the future (Model $2 ; n=430$ ), are shown in Table 6. Prior to running the binomial logit, different tests for checking potential multicollinearity among the explanatory variables in the model were conducted according to Gujarati and Porter [48], showing no significant interactions. The majority of explanatory variables in the model are categorical, so choosing a base case as a reference is needed to properly interpret the modeling results (see Table 6). This enables us to determine whether individuals' variables are statistically significant when compared to the base case. Subsequently, the last version of the model is shown once those explanatory variables that are not statistically significant are removed. To that end, multiple likelihood ratio (LR) tests have been conducted during the calibration process. Therefore, we ensure that the explanatory variables omitted have no impact on the overall fitting or the explanatory power of both of the models shown in Table 6. As expected, the statistical and practical significance of the coefficients is aligned with previous results of this research.

Table 6. Logit model results.

\begin{tabular}{|c|c|c|c|c|c|c|c|}
\hline \multicolumn{2}{|c|}{ Variables (Base Category) } & \multicolumn{3}{|c|}{$\begin{array}{l}\text { Model 1: Intention to Use Moped } \\
\text { Sharing (Base: Not Willing to Use) }\end{array}$} & \multicolumn{3}{|c|}{$\begin{array}{l}\text { Model 2: Vehicle Ownership Requirement } \\
\text { in the Future (Base: It Will Remain a Need) }\end{array}$} \\
\hline & & Coeff. & SE & $p$-Value & Coeff. & SE & $p$-Value \\
\hline \multirow{13}{*}{$\begin{array}{l}\text { Socioeconomic and } \\
\text { demographic variables }\end{array}$} & Age (From 18 to 25$)$ & & & & & & \\
\hline & From 26 to 34 & - & - & - & - & - & - \\
\hline & From 35 to 49 & - & - & - & - & - & - \\
\hline & Above 49 & -1.220 & 0.473 & 0.010 & -0.969 & 0.416 & 0.020 \\
\hline & Occupation (Student) & & & & & & \\
\hline & Employed & -1.748 & 0.557 & 0.002 & 1.072 & 0.337 & 0.001 \\
\hline & $\begin{array}{l}\text { Student and part-time } \\
\text { employee }\end{array}$ & -1.590 & 0.559 & 0.004 & - & - & - \\
\hline & $\begin{array}{l}\text { Housework, unemployed or } \\
\text { retired }\end{array}$ & -1.855 & 0.991 & 0.061 & - & - & - \\
\hline & $\begin{array}{l}\text { Monthly income (Below } \\
1000 \text { Euro) }\end{array}$ & & & & & & \\
\hline & 1000 to 2000 euro & - & - & - & -0.673 & 0.329 & 0.041 \\
\hline & Above 2000 Euro & - & - & - & - & - & - \\
\hline & $\begin{array}{l}\text { Without own income } \\
\text { Place of residence } \\
\text { (Outskirts/suburbs) }\end{array}$ & -1.691 & 0.537 & 0.002 & -0.992 & 0.305 & 0.001 \\
\hline & City center & - & - & - & 0.542 & 0.248 & 0.029 \\
\hline
\end{tabular}


Table 6. Cont.

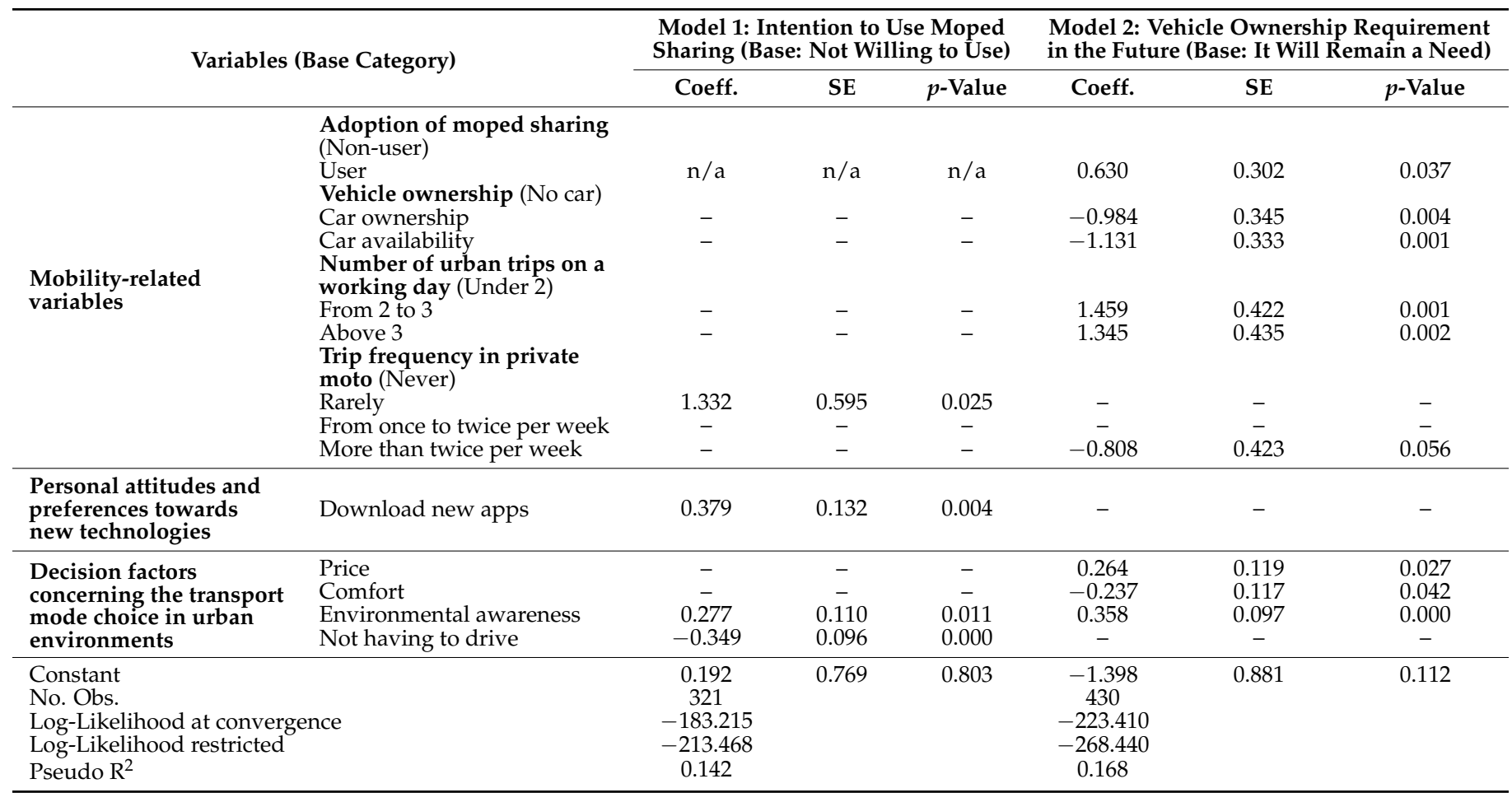

Concerning Model 1 (intention to use moped sharing), non-users of moped sharing services were asked whether they would consider using this mobility alternative in the future. Non-potential users of moped sharing systems, that is, those people not willing to use a shared moped in the future, were chosen as a reference. The model results confirm that, from a statistical point of view ( $p$-value $<0.05$ ), the potential use of moped sharing is more influenced by sociodemographic variables and attitudinal factors than by mobility-related variables.

As with the adoption of moped sharing, significant differences have been found across age categories. Compared to the base category (aged from 18 to 25), those individuals aged above 49 are less likely to use a shared moped in the future $(p$-value $=0.010)$. Similarly, a lower interest in adopting moped sharing is found among employed, housework, unemployed, or retired people, compared to students (young people). As expected, the results suggest a lower intention of using moped sharing services for individuals without their own income.

Regarding travel-related attributes, only the frequency of the use of private moto is an explanatory factor significantly determining the potential use of moped sharing. Those individuals rarely using private moto are significantly $(p$-value $=0.025)$ more likely to use moped sharing in the future, compared to those respondents never traveling by private moto. This finding would indicate that moped sharing systems are particularly interesting for people rarely traveling by moto, who may benefit from personal moped use without the responsibilities and costs of ownership.

According to the modeling results, those individuals feeling fairly comfortable with testing, downloading, and using new mobile services and applications are significantly $(p$-value $=0.004)$ more likely to adopt moped sharing in the future. Furthermore, the environmental awareness of individuals significantly $(p$-value $=0.011)$ increases the intention to use moped sharing services. This makes sense given that people more concerned about environmental issues are prone to support these kinds of sustainable urban transport. Finally, a lower preference for driving decreases the likelihood to use moped sharing in the future. 
As for Model 2 (individuals' opinions on whether owning a private vehicle will not be a need in the future), both moped sharing adopters and non-users were asked whether they consider that owning a private vehicle will not be a need in the future. People who opined that owning a private vehicle will remain a need in the future were chosen as the base reference. In this case, the model results confirm that, from a statistical point of view ( $p$-value $<0.05$ ), the opinion on the future role of vehicle ownership is influenced by sociodemographic variables and mobility-related attributes, as well as the importance according to certain decision factors.

Regarding sociodemographic characteristics, respondents aged above 49 , with middleincome and without their own income, are more pro-vehicle ownership in the future, while the opposite is found for employed individuals. As for residential location, according to the modeling results, this variable significantly influences the opinion towards whether owning a private vehicle will not be a need in the future. As seems reasonable, the propensity to vehicle ownership is significantly ( $p$-value $=0.029)$ lower for people living in the city center, given that these areas have a higher supply of mobility services. As discussed, moped sharing could play a role in reducing vehicle ownership by providing extra accessibility when public transit does not meet the riders' needs. This may discourage people from owning private vehicles.

More interestingly, moped sharing adoption emerges as a very important driver in the opinion towards whether owning a private vehicle will not be a need in the future $(p$-value $=0.037)$. Individuals adopting moped sharing seem to believe that vehicle ownership will not be a need in the future. These findings are in line with previous the results commented in Section 6.3. This trend is relevant because users of moped sharing perceive that these services can increase transportation opportunities and accessibility. This may impact on reducing vehicle ownership rates in cities in the coming years.

Some results concerning travel-related attributes are statistically significant at the $95 \%$ level of confidence. For instance, individuals who have a car available for their personal use consider that owning a private vehicle will remain a need in the future. We can also observe that individuals frequently using private moto show the same tendency, which is consistent. By contrast, individuals who make more than two trips during a weekday think that vehicle ownership will not be a need in the future.

Finally, we comment on the results concerning the level of importance given by individuals to different decision factors when choosing an urban mobility option. Factors potentially affecting mode choice, such as environmental awareness, comfort, and price, were found to be statistically significant when explaining whether owning a private vehicle will remain a need in the future. Accordingly, people more concerned about environmental issues when choosing an urban mobility option believe that vehicle ownership will not be a need in the future $(p$-value $=0.000)$.

Regarding the goodness of fit of the estimated results, the models showed a pseudo- $\mathrm{R}^{2}$ coefficient of 0.142 and 0.168 , which may be considered satisfactory for logit specifications according to Hensher and Bradley [49]. This result is comparable to the fit accuracy achieved in similar studies [50,51]. In addition, a likelihood ratio (LR) test was adopted to check that the final model is significant overall when compared to the empty model.

\section{Conclusions}

This paper has shown a first insight exploring the use and opinions towards moped sharing, using data collected from a web-based survey conducted in different Spanish cities. This analysis of the survey yielded some interesting conclusions.

First, the research showed the key role of sociodemographic variables on moped sharing usage (frequent, occasional, and potential users). According to the survey data, there seems to be a higher proportion of moped sharing users among males, young adults, people with a high education level, high mobility rates, and living in the inner urban areas (due to the area currently served by operators). Furthermore, age, occupation, income, and environmental awareness seem to be among the main reasons behind the potential 
use of these services in the future. This picture is interesting for both moped sharing operators and transport planners to target specific user market segments (both users and non-users with a higher probability to adopt these systems in the future). Thus, direct policy efforts could act on specific segments to promote this sustainable urban transport service. Additionally, these findings would indicate wider moped sharing adoption in the coming years, as the level of education increases and the urban population is more familiar with new technologies.

The second conclusion regards the impact of the advent of moped sharing on urban mobility. These services have positive impacts on urban transport as they may reduce the use of private vehicles, and therefore ameliorate the current problems of road congestion and scarcity of public space in urban environments. However, shared e-mopeds may also capture demand from public transit and active modes. Consequently, moped sharing services, in their current form, have an unclear net effect on urban sustainability. This fact underlines the importance of integrating moped sharing systems with public transport in order to promote their complementary use (including through intermodal trips, e.g., moped sharing would act as a feeder for the public transit network in areas with lower transit accessibility) and move urban mobility towards sustainability.

The last conclusion regards the motivations and barriers to the use of moped sharing. On the one hand, moped sharing users highlight that shared e-mopeds are easy to park, and are a flexible option to drive through narrow streets. Therefore, moped sharing seems to be particularly attractive when traveling around urban areas, mainly central districts/neighborhoods. In this line, expanding the area currently served was reported as one of the main priorities among moped sharing users. For this reason, policy efforts could act on promoting the extension of moped sharing to urban areas outside the central districts, given the potential benefits to urban livability. Particularly in large metropolitan areas, local authorities should support expanding the area served, since shared mobility seems to be less competitive in suburban environments. These new transport services could also be promoted as feeders for public transport, or could be reinforced in urban areas with low accessibility to public transport. On the other hand, the main barriers are related to the scarce familiarity with how to ride motorcycles/mopeds or the unawareness of moped sharing. Surprisingly, prices, registration process, or the area served were not perceived as the main barriers for not adopting moped sharing. All of this may indicate that the main barrier would be linked to having a first experience with a shared e-moped. To overcome this, planners and operators should explore formulas to provide individuals the first contact with this mobility alternative (for instance, operators could provide a trial period). In this way, a noticeable share of potential users could adopt this shared mobility option at a low cost.

From the results of this paper, some avenues can be pointed out for further research. Firstly, future contributions should increase the sample size, particularly concerning moped sharing users, by, e.g., combining online questionnaires with the following different surveying methods: personal interviews, phone surveys, etc. Additionally, the insight would be improved by covering other countries with lower penetration of moped sharing. It is also important to note that the survey campaign was conducted before the COVID-19 pandemic. Due to the changes in people's habits and travel behavior patterns [52], exploring the use of moped sharing in post-COVID-19 times is mandatory. In this regard, the fear of contagion could be a strong, and could be a recurrent reason for not choosing moped sharing services, and the provision of masks, gloves, sanitizer gel, and helmets with no contact with the mouth, nose, and eyes have been found relevant drivers for moped sharing users in Spain [52]. Furthermore, a more complex analysis employing econometric techniques would be needed to statistically identify the key variables determining the use of moped sharing through, e.g., latent class models, the value-belief-norm theory, the technology acceptance model, or to analyze the user behavior within a social environment. For this purpose, the design of an attitudinal survey is needed to capture psychological variables determining the use of shared moped services. Additionally, the adoption of 
shared e-mopeds together with other shared mobility modes should be explored as a whole more deeply, given the importance of understanding the differences in the current and future roles of moped sharing in urban transport sustainability, compared with other shared mobility modes. Finally, future research is needed to quantify the carbon footprint and the impacts of electric mopeds, regarding some components such as batteries.

Author Contributions: Conceptualization, Á.A.-G., J.G. and N.S.; methodology, Á.A.-G. and J.G.; software, Á.A.-G. and J.G.; validation, Á.A.-G. and J.G.; formal analysis, Á.A.-G.; investigation, Á.A.-G., J.G., N.S. and J.J.V.D.; resources, Á.A.-G., J.G., N.S. and J.J.V.D.; data curation, Á.A.-G.; writing-original draft preparation, Á.A.-G.; writing-review and editing, Á.A.-G., J.G. and N.S.; visualization, Á.A.-G.; supervision, J.G.; project administration, J.J.V.D. All authors have read and agreed to the published version of the manuscript.

Funding: This research was developed within the project Co-Mov, co-funded by Comunidad de Madrid (Spain), the European Social Fund, and the European Regional Development Fund, with grant number [Y2018/EMT-4818].

Institutional Review Board Statement: Not applicable.

Informed Consent Statement: Not applicable.

Data Availability Statement: Data under request.

Conflicts of Interest: The authors declare no conflict of interest. The funders had no role in the design of the study; in the collection, analyses, or interpretation of data; in the writing of the manuscript, or in the decision to publish the results.

\section{References}

1. Fulton, L. Three Revolutions in Urban Passenger Travel. Joule 2018, 2, 575-578. [CrossRef]

2. Circella, G.; Alemi, F.; Tiedeman, K.; Handy, S.; Mokhtarian, P. The Adoption of Shared Mobility in California and Its Relationship with Other Components of Travel Behaviour; Project Report; National Center for Sustainable Transportation, University of California: Davis, CA, USA, 2018. Available online: https://ncst.ucdavis.edu/project/the-adoption-shared-mobility-in-california-andrelationship-with-other-components-travel-behavior/ (accessed on 10 March 2020).

3. World Bank. World Development Indicators_Urban Population. Available online: https://data.worldbank.org/indicator/SP. URB.TOTL.IN.ZS (accessed on 15 September 2019).

4. WHO (World Health Organization). Ambient (Outdoor) Air Quality and Health. Available online: http://www.who.int/en/ news-room/fact-sheets/detail/ambient-(outdoor)-air-quality-and-health (accessed on 20 September 2018).

5. Howe, E.; Jakobsen, F.J. Unu Global Scooter Sharing Market Report. 2019. Available online: https://share.unumotors.com/ global-mobility-sharing-market-report (accessed on 14 April 2020).

6. Shaheen, S.; Cohen, A.; Zohdy, I. Shared Mobility: Current Practices and Guiding Principles; Report No. FHWA-HOP-16-022; U.S. Department of Transportation, Federal Highway Administration: Washington, DC, USA, 2016.

7. Henao, A. Impacts of Ridesourcing—Lyft and Uber-On Transportation Including VMT, Mode Replacement, Parking and Travel Behaviour. Ph.D. Thesis, University of Colorado, Denver, CO, USA, 2017.

8. Shaheen, S.; Cohen, A.; Yelchuru, B.; Sarkhili, S. Mobility on Demand Operational Concept Report; Report No. FHWA-JPO-18-611; Intelligent Transportation Systems Joint Program Office, U.S. Department of Transportation: Washington, DC, USA, 2017.

9. NASEM (National Academies of Sciences, Engineering, and Medicine). Shared Mobility and the Transformation of Public Transit; The National Academies Press: Washington, DC, USA, 2016. [CrossRef]

10. Shaheen, S.; Chan, N. Mobility and the sharing economy: Potential to facilitate the first- and last-mile public transit connections. Built Environ. 2016, 42, 573-588. [CrossRef]

11. Shaheen, S.; Cohen, A. Shared Micromoblity Policy Toolkit: Docked and Dockless Bike and Scooter Sharing. UC Berkeley Transp. Sustain. Res. Cent. 2019. Available online: https:/ / escholarship.org/uc/item/00k897b5 (accessed on 1 September 2019). [CrossRef]

12. Buck, D.; Buehler, R.; Happ, P.; Rawls, B.; Chung, P.; Borecki, N. Are bikeshare users different from regular cyclists? A first look at short-term users, annual members, and are cyclists in the Washington, DC region. Transp. Res. Rec. J. Transp. Res. Board 2013, 2387, 112-119. [CrossRef]

13. Rayle, L.; Shaheen, S.; Chan, N.; Dai, D.; Cervero, R.; University of California Transportation Center (UCTC). App-Based, On-Demand Ride Services: Comparing Taxi and Ridesourcing Trips and User Characteristics in San Francisco. UCTC-FR2014-08. 2014. Available online: https://www.its.dot.gov/itspac/dec2014/ridesourcingwhitepaper_nov2014.pdf (accessed on 20 March 2018).

14. Taylor, B.; Chin, R.; Melanie, C.; Dill, J.; Hoel, L.; Manville, M.; Polzin, S.; Schaller, B.; Shaheen, S.; Sperling, D.; et al. Between Public and Private Mobility: Examining the Rise of Technology-Enabled Transportation Services; Special Report 319; Transportation Research 
Board, The National Academy of Sciences: Washington, DC, USA, 2016. Available online: http://nap.edu/21875 (accessed on 4 April 2018).

15. Tyndall, J. Free-floating carsharing and extemporaneous public transit substitution. Res. Transp. Econ. 2019. [CrossRef]

16. Cohen, A.; Shaheen, S. Planning for Shared Mobility; PAS Report 583; The American Planning Association: Chicago, IL, USA, 2016. Available online: https:/ / www.planning.org/publications/report/9107556/ (accessed on 15 January 2017).

17. Machado, C.; de Salles Hue, N.; Berssaneti, F.; Quintanilha, J. An Overview of Shared Mobility. Sustainability $2018,10,4342$. [CrossRef]

18. Roukouni, A.; Homem de Almeida Correia, G. Evaluation Methods for the Impacts of Shared Mobility: Classification and Critical Review. Sustainability 2020, 12, 10504. [CrossRef]

19. Fishman, E. Bikeshare: A Review of Recent Literature. Transp. Rev. 2016, 36, 92-113. [CrossRef]

20. Médard de Chardon, C.; Caruso, G.; Thomas, I. Bicycle sharing system 'success' determinants. Transp. Res. Part A Policy Pract. 2017, 100, 202-214. [CrossRef]

21. Guo, Y.Y.; Zhou, J.B.; Wu, Y.; Li, Z.B. Identifying the factors affecting bike-sharing usage and degree of satisfaction in Ningbo, China. PLOS ONE 2017, 12, e0185100. [CrossRef]

22. Li, X.; Zhang, Y.; Sun, L.; Liu, Q. Free-Floating Bike Sharing in Jiangsu: Users' Behaviours and Influencing Factors. Energies 2018, 11, 1664. [CrossRef]

23. Bieliński, T.; Kwapisz, A.; Ważna, A. Bike-Sharing Systems in Poland. Sustainability 2019, 11, 2458. [CrossRef]

24. Bigazzi, A.; Wong, K. Electric bicycle mode substitution for driving, public transit, conventional cycling, and walking. Transp. Res. Part D Transp. Environ. 2020, 85, 102412. [CrossRef]

25. Efthymiou, D.; Antoniou, C.; Waddell, P. Factors affecting the adoption of vehicle sharing systems by young drivers. Transp. Policy 2013, 29, 64-73. [CrossRef]

26. Mishra, G.S.; Clewlow, R.R.; Mokhtarian, P.L.; Widaman, K.F. The effect of carsharing on vehicle holdings and travel behavior: A propensity score and causal mediation analysis of the San Francisco Bay Area. Res. Transp. Econ. 2015, 52, 46-55. [CrossRef]

27. Ko, J.; Ki, H.; Lee, S. Factors affecting carsharing program participants' car ownership changes. Transp. Lett. 2019, 11, 208-218. [CrossRef]

28. Shaheen, S.; Cohen, A.; Farrar, E. Carsharing's impact and future. Adv. Transp. Policy Plan. 2019, 87-120. [CrossRef]

29. Alemi, F.; Circella, G.; Handy, S.; Mokhtarian, P. What influences travellers to use Uber? Exploring the factors affecting the adoption of on-demand ride services in California. Travel Behav. Soc. 2018, 13, 88-104. [CrossRef]

30. Raktim Mitra, R.; Hess, P.M. Who are the potential users of shared e-scooters? An examination of socio-demographic, attitudinal and environmental factors. Travel Behav. Soc. 2021, 23, 100-107. [CrossRef]

31. Ratan, R.; Earle, K.; Rosenthal, S.; Hua Chen, V.H.; Gambino, A.; Goggin, G.; Stevens, H.; Li, B.; Lee, K.M. The (digital) medium of mobility is the message: Examining the influence of e-scooter mobile app perceptions on e-scooter use intent. Comput. Hum. Behav. Rep. 2021, 3, 100076. [CrossRef]

32. Howe, E.; Bock, B. Global Scootersharing Market Report. Innoz. 2017. Available online: https://www.innoz.de/sites/default/ files/howebock_global_scootersharing_market_report_2017.pdf (accessed on 15 December 2017).

33. Degele, J.; Gorr, A.; Haas, K.; Kormann, D.; Krauss, S.; Lipinski, P.; Tenbih, M.; Koppenhoefer, C.; Fauser, J.; Hertweck, D. Identifying E-scooter sharing customer segments using clustering. In Proceedings of the 2018 IEEE International Conference on Engineering Technology and Innovation (ICE/ITMC), Stuttgart, Germany, 17-20 June 2018; pp. 1-8. [CrossRef]

34. Aguilera-García, Á.; Gomez, J.; Sobrino, N. Exploring the adoption of moped scooter-sharing systems in Spanish urban areas. Cities 2020, 96, 102424. [CrossRef]

35. Pérez-Fernández, O.; García-Palomares, J.C. Parking Places to Moped-Style Scooter Sharing Services Using GIS LocationAllocation Models and GPS Data. ISPRS Int. J. Geo-Inf. 2021, 10, 230. [CrossRef]

36. Stephanou, K. The Rise of Scooter Sharing. Comodule. Available online: https://comodule.com/blog/the-rise-of-scooter-sharing (accessed on 11 December 2017).

37. Howe, E. Global Scootersharing Market Report. Innoz. 2018. Available online: https://www.innoz.de/sites/default/files/ global_scootersharing_market_report_2018.pdf (accessed on 21 December 2018).

38. Keogh, E. E-Scooter Sharing: A New Dimension of Individual Mobility. Revolve. Available online: http://revolve.media/escooter-sharing-a-new-dimension-of-individual-mobility/ (accessed on 10 December 2018).

39. Ferrero, F.; Perboli, G.; Rosano, M.; Vesco, A. Car-sharing services: An annotated review. Sustain. Cities Soc. 2018, 37, 501-5018. [CrossRef]

40. Tyfield, D. Putting the Power in "Socio-Technical Regimes"-E-Mobility Transition in China as Political Process. Mobilities 2014, 9,585-603. [CrossRef]

41. Casprini, E.; Paraboschi, A.; Di Minin, A. Social Media-Based Business Models: An Empirical Investigation on the BlaBlaCar it Case. In Casprini, E.; Business Model Innovation: Drivers, Processes and Capabilities. Ph.D. Thesis, Schuola Superiore Sant'Anna, Pisa, Italy, 2014.

42. Shaheen, S.; Stocker, A.; Mundler, M. Online and App-Based Carpooling in France: Analyzing Users and Practices. In Disrupting Mobility; Meyer, G., Shaheen, S., Eds.; Lecture Notes in Mobility; Springer: Cham, Switzerland, 2017. [CrossRef]

43. Lavieri, P.S.; Bhat, C.R. Investigating objective and subjective factors influencing the adoption, frequency, and characteristics of ride-hailing trips. Transp. Res. Part C Emerg. Technol. 2019, 105, 100-125. [CrossRef] 
44. Monzon, A.; Julio, R.; Garcia-Martinez, A. Hybrid methodology for improving response rates and data quality in mobility surveys. Travel Behav. Soc. 2020, 20, 155-164. [CrossRef]

45. Metropolitan Mobility Observatory. Metropolitan Mobility Observatory (MMO) Report Data. 2017. Available online: http: //www.observatoriomovilidad.es/images/stories/05_informes/informe_omm_2017_web2.pdf (accessed on 30 April 2019).

46. Ben-Akiva, M.E.; Lerman, S.R. Discrete Choice Analysis: Theory and Application to Travel Demand; MIT Press: Cambridge, MA, USA, 1985.

47. Ortúzar, J.D.; Willumsen, L.G. Modelling Transport. Modelling Transport, 4th ed.; John Wiley \& Sons: Chichester, UK, 2011. [CrossRef]

48. Gujarati, D.; Porter, D.C. Basic Econometrics, 4th ed.; McGraw-Hill: New York, NY, USA, 2004.

49. Hensher, D.A.; Bradley, M. Using stated response choice data to enrich revealed preference discrete choice models. Mark. Lett. 1993, 4, 139-151. [CrossRef]

50. Dill, J.; Wardell, E. Factors affecting worksite mode choice: Findings from Portland, Oregon. Transp. Res. Rec. 2007, 1994, 51-57. [CrossRef]

51. Thrane, C. Examining tourists' long-distance transportation mode choices using a Multinomial Logit regression model. Tour. Manag. Perspect. 2015, 15, 115-121. [CrossRef]

52. Awad-Núñez, S.; Julio, R.; Gomez, J.; Moya-Gómez, B.; González, J.S. Post-COVID-19 travel behaviour patterns: Impact on the willingness to pay of users of public transport and shared mobility services in Spain. Eur. Transp. Res. Rev. 2021, 13, 20. [CrossRef] 